\title{
Design parameters for seismically retrofitted masonry-to-timber connections: injection anchors
}

\author{
Susana Moreira ${ }^{1}$, Luís F. Ramos ${ }^{2}$, Daniel V. Oliveira ${ }^{3}$, Paulo B. Lourenço ${ }^{4}$ \\ ISISE, Department of Civil Engineering, University of Minho, Guimarães, Portugal
}

\begin{abstract}
Proper structural connections play an important role in ensuring seismic loads distribution and developing global damage mechanisms of structures. In historical unreinforced masonry buildings, effective connections between masonry walls and timber floors or walls through the use of anchors can prevent the occurrence of out-of-plane mechanisms and promote box-like behavior. Particularly for historic structures, injection anchors can comply with requirements as decreased architectural impact and minimum intervention. Therefore, this paper aims at developing structural design parameters and recommendations that allow the design of connections retrofitted with injection anchors, found in historical unreinforced masonry buildings, built during the $19^{\text {th }}$ century, in Portugal. Existing strength prediction formulae based on behavior models, and idealized force-displacement curves were developed to better fit the results obtained from a series of quasi-static monotonic and cyclic pullout tests carried out on pairs of injection anchors. Behavior models were able to approximate the experimental results, if adapted to the specificities of historical masonry. Further validation is needed, particularly for the combined cone-bond model. From the idealized curves, displacement acceptance criteria, expected forces, and behavior factors were proposed, according to the performance-based approaches recommended by EC8-Part 3 and ASCE/SEI 41-13. Finally, retrofit design recommendations were addressed.
\end{abstract}

Keywords: masonry-to-timber, connections, injection anchors, seismic retrofit, design, idealized curve, performance criteria, cyclic pullout test

${ }^{1} \mathrm{PhD}$ candidate, ISISE, Dep. of Civil Engineering, University of Minho, Campos de Azurém, 4800-058 Guimarães, Portugal. Phone: +351 253517 215, E-mail: su.moreira.pt@gmail.com (corresponding author)

${ }^{2}$ Assistant Professor, ISISE, Dep. of Civil Engineering, University of Minho, Campos de Azurém, 4800-058 Guimarães, Portugal. Phone: +351 253510 200, E-mail: lramos@civil.uminho.pt

${ }^{3}$ Associate Professor, ISISE, Dep. of Civil Engineering, University of Minho, Campos de Azurém, 4800-058 Guimarães, Portugal. Phone: +351 253510 247, E-mail: danvco@ civil.uminho.pt

${ }^{4}$ Full Professor, ISISE, Dep. of Civil Engineering, University of Minho, Campos de Azurém, 4800-058 Guimarães, Portugal. Phone: +351 253510 209, E-mail: pbl@civil.uminho.pt 


\section{INTRODUCTION}

The seismic vulnerability of unreinforced masonry (URM) buildings is well recognized in literature (Bruneau, 1994; Betti et al., 2014), as well as the importance of the connections between the primordial structural components, the masonry walls and the timber floors or walls (Tomaževič, 1999; Bento et al., 2005; Kim and White 2004). Even if the importance of their presence has been recognized for a long time as vital in developing appropriate box-behavior and global damage mechanisms, the topic has been successively "neglected" over time.

It is difficult to collect information about masonry-to-timber connections because usually they are not at sight on the finished building and drawings of old URM buildings are not available. On post-earthquake surveys, due to safety issues, assessment is conducted from outside the URM buildings, so no information is retrieved about the conditions of the connections and the timber diaphragm (Bruneau, 1994). To act on the conservation of historical buildings, it is of pressing importance to study the behavior of structural connections and to develop appropriate and engineered retrofitting solutions (Senaldi et al., 2014).

Since few works have been carried out on the topic (Algeri et al., 2010; Paganoni \& D'Ayala, 2014), it was necessary to start from scratch with an experimental campaign, which provided the much needed information to develop structural design tools. Under the scope of the FP7 European program NIKER (New integrated Knowledge based approaches to the protection of cultural heritage from Earthquake-induced Risk), two typologies of retrofit solutions for masonry-to-timber connections were developed in collaboration with the contractor Monumenta Ltd: tie-rods with anchor plates, and injections anchors. This paper focuses on the latter retrofit solution, which was initially developed to improve connections between masonry walls and timber framed walls, but can be extended to other types of connections found in masonry constructions, namely with timber floors.

The strengthening solution consists of a pair of injection anchors placed in pre-cored holes in the masonry wall. The timber elements go between the parallel injection anchors so that a symmetrical behavior can be explored, as shown in Figure 1a. The injection anchor itself is a steel rod inside a 
woven polyester based tubular sleeve, provided by the company $\operatorname{Cintec}^{\circledR}$, which is placed in a precored hole and injected, under low pressure, with a cementitious grout. The sleeve can expand to suit the diameter of the borehole, which can vary according to the steel bar diameter, and control the flow of grout into voids. The distance between anchors can vary according to the thickness of the timber elements and the steel gusset plates. These plates are bolted to both sides of the timber elements, so that they work as a double shear connection.

Assuming that the gusset/timber element connection can be designed using EC5 (CEN/TC 250/SC5 2004), it was decided that the study should focus solely on the strengthening solution itself. Thus the failure modes due to direct pullout of the injection anchors are the following (Arifovic \& Nielsen, 2004; Algeri et al., 2010): masonry cone breakout (FM1), failure of the interface masonry/grout (FM2), failure of the interface grout/steel tie (FM3), and yielding of the steel tie (FM4), as shown in Figure 1b. Since the grout used was cementitious, no chemical phenomena occurred in the interface between grout and masonry, consequently FM2 relies only on adhesion, friction and mechanical interlocking. In these particular anchors, the probability of occurrence of FM3 or FM4 is very low. The first is prevented by the presence of a washer at the free end of the anchor (opposing to the loaded end) encompassing most of the grout plug, and the second is limited by using a high grade steel. The failure modes described can occur individually or combined among themselves.

Construction details, materials and loading conditions of the specimens meant to replicate connections found on two typologies of URM buildings built during the $19^{\text {th }}$ century, in Lisbon, Portugal (Mascarenhas, 2004; Appleton, 2005), the so-called Pombalino Tardio and Gaioleiro, which are recognized for their seismic vulnerability (Cardoso et al.,2005; Lourenço et al., 2011). A study carried out by (Bento et al., 2005) acknowledged that anchoring the peripheral masonry walls to the inner timber framed walls would be an effective way of decreasing out-of-plane collapse of the masonry walls, and improve overall behavior.

Existing literature (Priestley, 2000), as well as EC8-Part 3 (CEN/TC250, 2004) and ASCE/SEI 41-13 (ASCE, 2014), suggest performance-based design as the most appropriate path towards assessment and design of seismic retrofit, since it establishes a direct relationship between 
design and expected structural system or component performance. In this paper, this matter was addressed through the analysis of idealized force-displacement curves obtained experimentally. These curves as simplified approximations to the experimental backbone curves facilitate their implementation in nonlinear procedures, and enable the determination of acceptance criteria. Depending on the components having a "brittle" or "ductile" behavior to a specific action, these criteria can be specified in force or displacement, respectively. In addition, since common practice is more oriented towards force-based design, the applicability of existing strength prediction formulae for injection anchors was assessed and design recommendations were proposed. The development of this kind of tools is essential towards a systematic approach to experimental data exploitation, promotion of appropriate retrofit design techniques, and inclusion of the connections behavior in the overall seismic response of a building.

This paper reflects the various steps taken towards the objectives described previously, starting with a description of the experimental campaign, followed by the discussion of appropriate strength prediction formulae, and the construction of idealized force-displacement curves and respective performance criteria for the performed tests. It concludes with the application of the main findings with the proposal of design recommendations.

\section{EXPERIMENTAL CAMPAIGN}

A brief introduction is presented here regarding the quasi-static monotonic and cyclic pullout tests performed on the pairs of injections anchors. Further detailed information can be found in Moreira et al. (2014).

\subsection{Specimens and test setup}

Two rubble masonry walls were hand constructed by professional masons, and were constituted by limestone of different sizes (maximum dimension of $0.20 \mathrm{~m}$ ) with poor mortar joints, at most $0.05 \mathrm{~m}$ thick. The proportion used was 1:3:10:6 (cement: hydraulic lime: river sand: clay rich sand, in volume), in order to obtain masonry mechanical properties closer to the ones described for historical constructions from the area. The dimensions of the walls resulted from the compromise between the 
hypothesized failure modes (see Figure 1b) and laboratory resources availability. Particularly, the value of the thickness chosen reflects common wall thicknesses found on the upper floors of the typology of buildings under study. Thus, each masonry wall was $2.0 \mathrm{~m} \mathrm{long}, 1.6 \mathrm{~m}$ high, and $0.4 \mathrm{~m}$ thick, as shown in Figure 2. On each masonry wall were installed four pairs of injection anchors, constituting then four specimens per wall (total of eight specimens).

The injection anchors were placed horizontally, in pre-cored holes of $50 \mathrm{~mm}$, spaced of $300 \mathrm{~mm}$, considering that a $120 \mathrm{~mm}$ thick timber framed wall could fit between them (see Figure 2). The steel ties that are part of the anchors were in stainless steel AISI 304 class 80 (EN designation 1.4301 gr.8.8), and had a diameter of M20 (Wall 1) and M16 (Wall 2). The denomination used to properly identify the specimens was composed by: "WT" standing for wall-to-timber element connection, " 40 " representing the thickness of the masonry wall in cm, "I" referring to the injection anchors, numbers "1" or " 2 " as a reference to the wall number, and a letter from "A" to " $\mathrm{D}$ " indicating the location of the anchors on the wall (see Figure 2). Four pairs of injection anchors were installed in each wall, allowing four tests on each wall sample.

Considering laboratory limitations in terms of space as well as the size of specimens, it was possible to develop a self-balanced test apparatus capable of simultaneously pulling out both anchors and redirecting the pullout force back to the specimen, as shown in Figure 2. In order to simulate a compression state of $0.2 \mathrm{MPa}$ on the walls resulting from permanent loads, four hydraulic actuators were placed over rigid steel profiles on top of the walls (see Figure 2). Since the installation of the injection anchors until testing, the compression state was kept constant through manual control of the pressure. The test was carried under displacement control, with increasingly higher amplitude cycles, from $0.5 \mathrm{~mm}$ to $18 \mathrm{~mm}$. Unloading occurred until $0.5 \mathrm{~mm}$ were reached on the control transducer in the actuator.

\subsection{Material mechanical properties}

The material characterization campaign comprehended: tensile tests on the steel ties from the injections anchors; compression tests on mortar samples, limestone cores, and masonry prisms; as well as diagonal compression tests on masonry wallets. 
The results obtained from the tensile tests on the steel ties of the injection anchors were according to the mechanical specifications of an AISI 304 class 80 . The nominal values adopted for further study of the anchors are: a $0.2 \%$ proof stress, $f_{\mathrm{y}}$, of $662 \mathrm{MPa}$ and an ultimate tensile strength, $f_{\mathrm{u}}$, of $870 \mathrm{MPa}$. The average elastic modulus determined was $197 \mathrm{GPa}$.

Samples of mortar were collected during construction of the walls that are part of the connections' specimens and were tested at the age of 400 days (same time of testing of the specimens), presenting an average compressive strength of $1.3 \mathrm{MPa}$ (cylinders). The limestone cores were tested in cylinders with a height/diameter ratio of 2 and an average compressive strength of $106.7 \mathrm{MPa}$ was obtained. The average elastic modulus was $51466 \mathrm{MPa}$. The masonry prisms and wallets attempt to be representative of the masonry walls that are part of the specimens, therefore the materials, arrangement, construction method, and the masons were the same in both situations. From the compression tests on the prisms, one obtained an average compressive strength of $1.8 \mathrm{MPa}$ and an elastic modulus of $1015 \mathrm{MPa}$. The diagonal compression tests provided the average values of 0.14 $\mathrm{MPa}$ and 0.29 MPa for the tensile and shear strengths, respectively, which were calculated according to Frocht (1931) theoretical approach.

The cementitious grout used in the injection anchors, Cintec's Presstec ${ }^{\mathrm{TM}}$ grout, is part of their standard anchoring solution, and was provided directly by the company, therefore it was not tested. It presents a tensile strength of 4.5 MPa and a compressive strength of $51.5 \mathrm{MPa}$, both at 28 days (values provided by $\mathrm{Cintec}^{\circledR}$ ). The installation of the anchors in the specimens was carried out by Cintec's technicians, stressing the fact that all procedures were taken to obtain their standard properties.

\subsection{Results}

The main results of the two monotonic and five quasi-static cyclic pullout tests on wall-to-timber elements connections strengthened with pairs of injection anchors are presented in Table 1. There is a significant difference, of approximately $30 \%$, in the maximum pullout force, $F_{\max }$, (to pull both anchors simultaneously) between tests conducted at the top and at the bottom of the wall. At the 
bottom of the wall, the average maximum pullout force was equal to $107.9 \mathrm{kN}$, while at the top the same parameter reached $76.8 \mathrm{kN}$, both with a $\mathrm{CoV}$ below $5 \%$.

Displacements and other parameters presented in Table 1 account for the combined behavior of both anchors. The initial stiffness $\left(k_{0}\right)$, the yield displacement $\left(d_{\mathrm{y}}\right)$, and the ultimate displacement $\left(d_{\mathrm{u}}\right)$, referring to the pair of injection anchors, were estimated based on the total slip $\left(s_{\mathrm{T}}\right)$, which results from the difference between the average out-of-plane displacement of both anchors and the masonry wall at the back face. The displacement $s_{\mathrm{T}}$ should reflect all the damage occurred on the specimen (masonry cracking and interface sliding). The calculation of $k_{0}$ was done with a linear least squares fit on the linear portion of the ascending branch of the first cycle of the $2 \mathrm{~mm}$ step. The yield displacement was taken as the displacement when first yielding occurs and the ultimate displacement corresponded to the post-peak displacement when a loss of $20 \%$ load carrying capacity happened (Park 1989). The ratio between $d_{\mathrm{u}}$ and $d_{\mathrm{y}}$ is the displacement ductility factor, $\mu$, which expresses the energy dissipation capacity of the strengthening solution. The initial stiffness and displacements display great variability, with $\mathrm{CoV}$ ranging from $5 \%$ to $75 \%$. Specimens at the bottom of the wall have a smaller ductility factor than the ones at the top. The ductility factor determined for specimen WT.40.I.1D was very high when compared to the other specimens, probably due to a different arrangement of the masonry and of the grout/masonry interface.

The force-displacement curves of specimens at the top and bottom of the wall are present in Figure 3. As can be observed, the pinched hysteresis loops showed great similarity, and were controlled by bond slip phenomena at the grout/masonry interface. The cyclic behavior showed a degradation of force and stiffness with the increasing steps and an accumulation of residual displacements. The descending branches of the cycles pushed the specimen as much as $0.5 \mathrm{~mm}$, which caused the development of compressive forces. The values of these forces obtained for top and bottom of the walls were very close $(-21 \mathrm{kN}$ and $-30 \mathrm{kN}$, respectively), not portraying the clear distinction noticed for tension. Residual displacements and compression forces depend greatly on the composition of the interface grout/masonry and surrounding masonry. 
All tests showed combined cone-bond failure with sliding at the interface grout/masonry (FM2) and masonry breakout (FM1). Tests at the top showed a higher influence of the masonry cone while tests at the bottom showed bond failure at the interface grout/masonry as the major contributor for failure (Moreira et al., 2014). Differences between tests performed at the top and bottom of the wall are most probably due to distinct boundary conditions. Lower out-of-plane displacements of the walls, higher pullout force, lower ductility and shape of the force-displacement curves support the explanation that the bottom of the wall behaves like a fixed support, while the top resembles a roller support.

\section{STRENGTH PREDICTION FORMULAE}

The mechanism associated with the wall-to-timber elements connections with injection anchors is assumed to work in series, being the load transmitted first from the timber elements to the steel tie, secondly to the interface tie/grout, in third place to the grout, then to the interface grout/masonry, and finally to the masonry. Depending on the properties of the masonry and interfaces, isolated or combined cone-bond failures can occur. Since masonry and concrete are quasi-brittle materials and the installation and design of anchors in concrete has been widely studied, one can explore some similarities in behavior to study the behavior of anchors in masonry (Obata et al.,1998; Eligehausen and Sawade 1989).

Anchors installed in concrete are usually divided in two main groups: cast-in-place and postinstalled. Cast-in-place anchors are installed before the concrete is casted while post-installed are applied in hardened concrete. Within these two groups there are sub-categories, but this study will focus on post-installed bonded anchors with cementitious grout (Cook et al., 2003). Post-installed anchors (bonded or mechanical) are a viable option to strengthen historical structures because they allow for minimum intervention and architectural impact on the structure. As previously mentioned, bonded anchors can be adhesive or grouted. Adhesive anchors are usually applied in situations that require fast setting times and have predrilled holes with small dimensions - up to 10 to $25 \%$ larger than the diameter of the steel anchor rod (Cook et al., 1998). Grouted anchors usually apply 
cementitious or polymer based grouts with predrilled holes typically 50 to $200 \%$ larger than the diameter of the steel anchor (Cook et al., 2003). The grout used can be a polymer, cementitious, or lime based, being the first one applied when dry conditions of the hole are required. The steel rod can be unthreaded or threaded with a nut and a headed bolt, or can even be a deformed reinforcing bar with or without end anchorage (Cook et al., 1998).

Bonded anchors mainly take advantage of bond and mechanical interlock (CEB, 1994; Cook et al., 2003). The presence of a head on the anchor changes the load transfer mechanism and has direct consequences on the failure modes. The most common failure modes for unheaded anchors are bond failure at rod/grout interface and bond failure at grout/substrate (concrete or masonry) interface. The existence of the head prevents the failure at the rod/grout interface and adds two more possible failure modes: substrate cone breakout and combined cone-bond failure (Zamora et al., 2003), as shown in Figure 4. Headed or not, bonded anchors can also fail by yielding of the steel rod, which can be controlled by properly choosing the steel grade and diameter. These failure modes are confirmed extensively in literature, mainly with the works of Zamora et al. (2003) and Cheok \& Phan (1998) citing Eligehausen et al. (1984a, 1984b).

With injection anchors in masonry, CEB (1994) states that they are mainly used for low compressive strength (lightweight and aerated concrete) and in perforated brick or hollow block masonry, which is consistent with the base material considered in the ETAG 029 (EOTA 2010). Load transfer mechanisms for these particular anchors can involve mechanical interlocking between injection anchor and masonry substrate, local mechanical interlocking between injection mortar and voids, and bond and friction between sleeve-grout and surface of the drilled hole. The use of an expandable sleeve around the anchor rod is commonly used to control the flow of mortar into voids. This effect of the sleeve, combined with the fact that the bearing walls are continuously under compression may introduce pre-compression to the grout - allowing for load transfer through friction between sleeve-grout interface and the surface of the drilled hole (and to adjust to possible internal voids, which increases the pull out strength capacity). The tests discussed in this paper used an 
expandable sleeve on walls that were in compression for the installation and testing of the anchors to best represent in situ conditions.

\subsubsection{Steel tie failure}

In reality, the steel tie is subjected to shear and bending stresses that might precipitate failure, but since the force was applied in the direction of the longitudinal axis of the steel tie and from its total length, only $17 \%$ was outside the wall, one can considers that the tensile stresses on the tie came mostly from direct tension. Therefore, Equation (1) can be used for the prediction of the nominal tensile strength by steel failure, $N_{\text {sa }}$.

$N_{s a}=n A_{s} f_{u}$

where $n$ is the number of anchors, $A_{s}$ is the stressed cross-section of steel, and $f_{u}$ is the steel ultimate tensile strength (nominal value). Considering $n$ equal to 2 , the diameters of the tie rods used experimentally, $\phi 16$ and $\phi 20$, and the average $f_{\mathrm{u}}$ obtained experimentally, $870 \mathrm{MPa}$, the respective tensile strengths associated with steel failure would be $350 \mathrm{kN}$ and $547 \mathrm{kN}$. For design purposes, the ACI 530 (ACI 530, 2005) proposes the use of the $0.2 \%$ proof stress, $f_{\mathrm{y}}$, rather than the ultimate one, and the application of a design reduction factor, $\phi$, of 0.90 . On the other hand, the ACI 318 (ACI 318, 2005) recommends the use of the tensile strength, but it should not be taken greater than the smaller of $1.9 f_{\mathrm{y}}$ and $860 \mathrm{MPa}$. It suggests a lower reduction factor (0.75), which is consistent with the use of a higher value for $f_{\mathrm{y}}$.

\subsubsection{Masonry cone breakout}

Since the mid-1970s, different design methods have been developed for anchorage to concrete, based mainly on plasticity models (modified Coulomb failure condition) and on linear elastic fracture mechanics (LEFM) (Zamora et al., 2003; Fuchs et al., 1995). Zamora et al. (2003) stated that headed grouted anchors are expected to behave similarly both with cast-in-place headed anchors and post-installed headed adhesive anchors. The first models were developed for headed anchors using plasticity type models as per ACI 349 (1990) and the VAC Method, which idealized a maximum 
tensile stress, distributed uniformly on the projected area of a certain angle stress cone radiating from the free end of the anchor towards the loaded end (Farrow \& Klingner, 1995). For the first method, the opening angle is $45^{\circ}$, while for the second method the angle varies. These models rely on the estimation of the tensile strength, $f_{\mathrm{t}}$, from the compressive strength, $f_{c}^{\prime}$ (the nominal concrete cylinder compressive strength on $150 \mathrm{~mm}$ by $300 \mathrm{~mm}$ cylinders) and on the effective embedment length, $h_{\mathrm{ef}}$. When the anchor is located near a free edge or is included in a group of anchors where the cone intersects the edge or overlaps another cone, the reduction in tensile capacity is accounted for with the introduction of the geometric factor $\frac{\mathrm{A}_{N c}}{A_{N c o}}$. This ratio between the actual projected area of anchor or anchor group $\left(A_{N C}\right)$ and the projected area of one anchor not limited by edge or spacing influences $\left(A_{N c o}\right)$ is present in Equations (5) to (7) in Table 2.

The plasticity theory used in ACI 349 (1990) is also applied to compute the nominal strength corresponding to brick masonry breakout of headed anchors, according to ACI 530 (ACI 530 2005), as presented in Equation (4) in Table 2. It idealizes a maximum tensile stress of $f_{t}=0.33 \sqrt{f_{m}^{\prime}}\left(f_{m}^{\prime}\right.$ is the nominal compressive strength in MPa for masonry), distributed uniformly on the projected area of a $45^{\circ}$ angle stress cone radiating from the free end of the anchor towards the loaded end. The issue related to overlapped areas of adjacent anchors is accounted for in $A_{\mathrm{Nc}}$, by subtracting one-half of the overlapping area in the projected area of each anchor, $A_{\mathrm{pt}}$. The approach is conservative when accounting for the influence of the edges of the masonry member, since it considers for $A_{\mathrm{pt}}$ the minimum of the two areas: $\pi h_{e f}^{2}$ (calculated from the effective embedment length) and $\pi c_{a}^{2}$ (calculated from the minor edge distance, $c_{\mathrm{a}}$ ).

Tomaževič (1999), considering past experimental campaigns to assess existing stone masonry mechanical properties, proposes the following two ranges of characteristic values or the tensile strength, $f_{\mathrm{tk}}$, and the compressive strength, $f_{\mathrm{mk}}$, respectively: $0.08 \mathrm{MPa}-0.21 \mathrm{MPa}$ and $0.30 \mathrm{MPa}-$ $0.90 \mathrm{MPa}$ (average values can be estimated, by multiplying $f_{\mathrm{tk}}$ and $f_{\mathrm{mk}}$ by 1.2 ). In order to maintain the philosophy of all formulations, with respect to the estimation of $f_{\mathrm{t}}$ through $f_{\mathrm{m}}$, one used the previous intervals and estimated one interval, $[0.08 ; 0.33] \sqrt{f_{m}}$, which reflects that relationship. The upper boundary of the interval coincides with the value present in Equation (4) in Table 2, which indicates 
that the expression might lead to overestimation of the tensile capacity of anchors installed in historical masonry. In addition, the latter mentioned equation should take into account overlapping areas of adjacent anchors and distances to the edge of the masonry element similarly to the concrete expressions, in order to better quantify the projected area. These recommendations are reflected in Equation (2) for the estimation of the tensile load associated with masonry cone breakout, $N_{\mathrm{c}}$.

$N_{c}=\frac{\mathrm{A}_{\mathrm{Nc}}}{\mathrm{A}_{\mathrm{Nco}}} \mathrm{A}_{\mathrm{Nco}} \cdot \mathrm{f}_{\mathrm{t}}=\frac{\mathrm{A}_{\mathrm{Nc}}}{\mathrm{A}_{\mathrm{Nco}}} \mathrm{k}_{1} \mathrm{~A}_{\mathrm{Nco}} \sqrt{\mathrm{f}_{\mathrm{m}}^{\prime}} \quad$ with $\quad 0.08 \leq k_{1} \leq 0.33$

From pullout tests of bonded anchors installed in clay brick masonry, Arifovic \& Nielsen (2004) calibrated an equation, also based on the plasticity theory, that turned out to be equal to the expression proposed in the ACI 349 (1990), as presented in Equation (5) in Table 2.

Several authors compared the previous design models with experimental data and demonstrated that they predict non-conservative estimates of the capacity for typical embedment lengths due to the assumption that the failure area increases with $d^{2}$ (Ballarini et al., 1986; Eligehausen \& Sawade, 1989; Fuchs et al., 1995; Piccinin et al., 2010). Same authors denoted the importance of the size effect and consequently, developed prediction equations for the failure load using linear fracture mechanics. With the application of LEFM, the nominal stress at failure decreases in proportion to $1 / \sqrt{h_{e f}}$ and failure load increases with $h_{e f}^{1.5}$. Fuchs et al. (1995) introduced this methodology through the concrete capacity design (CCD) method and determined experimentally the value of the factor $k_{c}$ for different types of anchors, which relates fracture toughness with the tensile strength. The value of $k_{\mathrm{c}}$ is obtained empirically, thus varying with units, with the type of anchor used, substrate, and other characteristics of the specimen that can affect failure. Zamora et al. (2003) determined experimentally the most suitable $k_{c}$ (as 12.6) for headed grouted anchors, as presented in Equation (6) in Table 2.

The CCD idealizes the failure cone as being a pyramid at $35^{\circ}$ radiating from the free end of the anchor to the loaded end. Consequently, the projected area is a square instead of a circle, as adopted for ACI 349 (1990), which facilitates the calculation of overlapping areas and reduced areas due to free edge effects. The CCD method combines the physical visualization of the cone failure with the accuracy of the $\psi$-method, which reflects the influence of certain parameters by applying factors to the 
strength of a single anchor. These factors account for geometric alterations on the projection area (free edge, spacing between anchors, etc.), the influence of edges of the concrete member on the distribution of stresses in the concrete $\left(\psi_{s, N}\right)$, and for the group effect when different tension loads are imposed to the individual anchors of a group - eccentricity $\left(\psi_{e c, N}\right)$, see Equation (6) in Table 2. This method is adopted by fib Bulletin No. 58 (CEB, 2011), EOTA-TR 029 (2007), and ACI 318 (2005), to determine the design value of the concrete conical failure, including for bonded anchors.

Allen et al. (2000) discussed the provisions for the calculation of the design tensile strength of headed anchors, noting the well-established plasticity approach presented previously, but also introducing a LEFM approach, similar to the one already adopted for the design of anchorage in concrete, as shown in Equation (7) in Table 2. The factor $k_{\mathrm{c}}$ has an equivalent $0.418 k$, and $k$ can take values from 10 to 24 , depending if it is a cast-in-plane or post-installed anchor and the type of masonry (clay bricks or concrete blocks). When used for design, the previous equations are multiplied by a strength reduction factor, $\phi$, of 0.5 , which is specific for masonry breakout, as suggested by ACI 530 (ACI 530, 2005).

All formulations presented concern uncracked concrete and masonry. Design for cracked concrete requires the application of an additional reduction factor. On the contrary, ACI 318 (ACI 318, 2005) provides expressions that determine the basic concrete breakout strength in cracked concrete, which can be affected by a factor reflecting uncracked state. Cracks affect anchor-to-concrete load transfer, so typical force-displacement curves in cracked concrete present lower strength and stiffness. The reduction of concrete failure cone load varies with the type of anchor, ranging from $25 \%$ (headed and undercut anchors) to 35\% (torque-controlled expansion anchors), when located in or close to cracks with a width from 0.3 to $0.4 \mathrm{~mm}$ (Eligehausen \& Balogh, 1995). Since the transfer load mechanism is similar for anchors in masonry, a reduction in load and stiffness is also expected. When designing anchors for seismic loads, concrete or masonry should always be considered cracked, see fib Bulletin No.58

(CEB, 2011). Several studies mentioned by Cheok \& Phan (1998) suggest that the tensile capacity of anchors is reduced from $10 \%$ to $20 \%$, when subjected to a cyclic or dynamic actions. 


\subsubsection{Bond failure mode}

There are two types of bond stress models: the elastic bond stress models and the uniform bond stress models. The latter is more appropriate for strength design methods and suitable for shallow embedments (prone to cone failure) as well as deeper embedments (prone to combined cone/bond failure). It also has the advantage of being more user friendly (Cook et al., 1998). Therefore, is also recommended by the fib Bulletin No.58 (CEB 2011) and EOTA-TR 029 (2007).

Equation (3), proposed by Zamora et al. (2003) to estimate the tensile force due to bond failure at the grout/masonry interface, $N_{\mathrm{b}}$, resulted from alterations to the originally proposed expression, by Cook et al. (1998), which used the uniform bond stress model to estimate the strength capacity associated with failure occurring at the steel tie/grout interface of adhesive anchors. The load-carrying capacity is linearly related to $h_{e f}$, the hole diameter $d_{0}(\mathrm{~mm})$, and the nominal value for the uniform bond stress (MPa) at the grout/concrete, $\tau_{0}^{\prime}$. Zamora et al. (2003) confirmed that for headed grouted anchors, the use of the hole diameter with the corresponding bonding stress is more appropriate than the steel rod diameter used in Cook's (1995) expression, since $d_{0}$ is usually $50 \%$ or more larger than $d$. For injection anchors in masonry this would be the case, thus the consideration of the hypothesis of applying this formulation to the current study. The disadvantage of this method is the lack of information regarding the bond strength of the interface, which needs to be available in the product approval standard. Cook \& Konz (2001) stated that bond strength is affected by internal factors (chemical formulation, manufacturing processes, and packaging) that are beyond the control of the designer and external factors within the control of the designer, such as the condition of the drilled hole during installation: (1) cleaned, damp, or wet; (2) the strength and type of coarse aggregate of the concrete base material; (3) short-term adhesive curing; and (4) loading at an elevated temperature. The condition of the drilled hole during installation, curing of the grout, and typology of masonry also have influence on the performance of injected anchors. To take this into account, during design the previous equations are multiplied by a strength reduction factor, $\phi$, of 0.65 , which is specific for pullout failure, as suggested by ACI 530 (ACI 530, 2005). 
$N_{b}=\tau_{0}^{\prime} \pi \mathrm{d}_{0} \mathrm{~h}_{\mathrm{ef}}$

Algeri et al. (2010) performed a series of monotonic pull-out tests on injection anchors with sleeves (similar to the ones used in the pullout tests described previously), installed in different types of masonry walls. The tests varied the bulb shape of the anchor, embedment length, and grout type (cement or lime based). The nominal bond strength of the interface grout/masonry was characterized and the following values were obtained for different substrates: $1.34 \mathrm{MPa}$ for solid limestone; 0.53 $\mathrm{MPa}$ for Credaro limestone; and 1.64 MPa for Zorzino limestone. These values are considerably lower, when compared to bond strength values at the (cementitious) grout/concrete interface found by Zamora et al. (2003).

\subsubsection{Combined cone-bond failure mode}

The combined cone-bond failure model results from the necessity to express analytically what was observed in experimental tests with adhesive anchors (Cook et al., 1998), which was the formation of a masonry cone close to the loaded end of the anchor combined with sliding of the remaining anchorage length not covered by the cone. Its complexity relies on the determination of the transition point between failure models. Cook et al. (1998) proposed combining the two contributions, masonry cone breakout and bond failure, in a two terms equation, with the cone depth, $h_{\mathfrak{c}}$, corresponding to the minimum load to produce failure, see Equation (8) in Table 3 for a single anchor. The depth $h_{\mathrm{c}}$ depends on the diameter of the anchor, the bond strength at the interface, and the compressive strength of the masonry. The balance between these variables determines if there is only the formation of the masonry cone $\left(h_{\mathrm{ef}} \leq h_{\mathrm{c}}\right)$ or a combined failure $\left(h_{\mathrm{ef}}>h_{\mathrm{c}}\right)$. When the cone depth $h_{\mathrm{c}}$ is very small, one can assume that there is only bond failure.

Since this was the failure mode observed experimentally, one decided to propose an equation that could express the force associated with the combined effect for a pair of parallel anchors, $N_{\text {cb }}$. Following the same principles, the difficult challenge is to calculate $h_{\mathrm{c}}$, considering that it can be overlapping between projected areas. Determining the cone depth, $h_{\mathrm{c}}$, is not straightforward and involves elaborate derivatives, if the combined expression takes into account circular projected areas. 
For design purposes, one proposes the estimation of $h_{\mathrm{c}}$ considering projected quadrangular areas, resultant from a pyramidal masonry failure at $45^{\circ}$. Then, for the calculation of the masonry cone capacity one can use $A_{\mathrm{Nc}}$, resulting from circular projection areas. The cone depth $h_{\mathrm{c}}$ continues to depend on the parameters mentioned previously, but now it also varies with the distance $s$ between anchors. In fact, the inequality $s \leq 2 h_{c}$ has to be verified, so that there is overlapping of projection areas. Mathematically, $h_{\mathrm{c}}$ can result in a negative value or larger than the effective embedment length $h_{\mathrm{ef}}$, but physically $h_{\mathrm{c}}$ has to respect the condition $0 \leq h_{c} \leq h_{e f}$. If negative, $h_{\mathrm{c}}$ takes the value zero and only bond failure occurs. If $h_{\mathrm{c}}$ is higher than $h_{\mathrm{ef}}, h_{\mathrm{c}}$ takes the value of $h_{\mathrm{ef}}$ and only masonry breakout failure occurs. When used for design, each term of Equations (8) and (9) in Table 3 should be multiplied by the appropriate strength reduction factor, $\phi$, which would be 0.5 for the masonry breakout contribution and 0.65 for the bond failure one, as suggested by ACI 530 (ACI 530, 2005).

\subsubsection{Application to the experimental results}

A comparison between the experimental results and the most appropriate existing strength prediction formulas for pull-out capacity was performed, which is evidenced in Figure 5 and Table 4. The tensile strength of the masonry, if calculated from $0.33 \sqrt{f_{m}^{\prime}}$ is in this case equal to $0.44 \mathrm{MPa}\left(f_{m}^{\prime}=\right.$ 1.8 MPa). This value is 3.14 times higher than the average value obtained from the diagonal compression tests performed on masonry wallets representative of the walls' masonry, $0.14 \mathrm{MPa}$. This confirms what was already discussed previously in subsection 3.1 .2 that $k_{1}$ equal to 0.33 is excessive and a lower value is required for a more realistic approach. For this particular case, a tensile strength of $0.14 \mathrm{MPa}$ corresponds approximately to $k_{1}$ equal to $0.1\left(0.1 \sqrt{f_{m}}\right)$, which falls within the proposed range, closer to the lower bound.

For comparison purposes, the estimation using Equation (4), regarding ACI 530 (2005), was applied using $0.33 \sqrt{f_{m}^{\prime}}$ for the tensile strength. When applying the updated version of the latter equation, which is Equation (2), a value equal to $0.14 \mathrm{MPa}\left(0.1 \sqrt{f_{m}}\right)$ was then applied. The full embedment length was assumed as effective and the value used for calculations was the average of embedment lengths measured on the injection anchors tested, which was equal to $333 \mathrm{~mm}$. The 
remaining two geometric characteristics took the following values: $d_{0}=50 \mathrm{~mm}$ and $s=300 \mathrm{~mm}$. In the bond models, pull-out strength was determined from three values of $\tau_{0}$, two of them proposed by Algeri et al. (2010) - 0.53 MPa (minimum) and 1.64 MPa (maximum) - and a third one equal to 0.90 MPa, estimated from the pull-out tests carried out at the top of the wall. Following the experimental evidences, the cone breakout models were used to predict the pullout capacity obtained on the tests performed at the top of the wall, $N_{\exp }^{T}$ and the bond failure models were used to estimate the pullout capacity for the tests at the bottom of the wall, $N_{\exp }^{B}$. The combined cone-bond model proposed previously should provide the better approximation to the experimental results, consequently its validity against both experimental values is discussed.

Equation (9) for the proposed combined cone-bond model and the value of $N_{\text {exp }}^{T}, 76.8 \mathrm{kN}$ were used, to estimate $h_{\mathrm{c}}$ and respective $\tau_{0}$, and to assess if they confirm what was observed experimentally and are within reasonable intervals. The values obtained were, respectively, $177.4 \mathrm{~mm}$ and $0.90 \mathrm{MPa}$. The first corresponds to $53 \%$ of $h_{\mathrm{ef}}$, which is close to the minimum cone depth obtained experimentally (approximately $180 \mathrm{~mm}$ ), and the second is within the values determined by Algeri et al. (2010), indicating that the proposed combined cone-bond model for parallel pairs of injection anchors in historical masonry performed adequately for the tests at the top of wall. Using the newly estimated $\tau_{0}$ and assuming a minimum shallow cone depth of approximately $50 \mathrm{~mm}$ (as observed in a number of specimens), the proposed model predicted a pullout capacity equal to $88.9 \mathrm{kN}$ (error of 18 $\%$ to $N_{\text {exp }}^{B}, 107.9 \mathrm{kN}$ ), if a factor of 2 was applied to $f_{\mathrm{t}}$, reflecting the confinement at the base of wall. Further analysis is needed, to understand if the confinement effect at the base of the masonry wall or the compressive state of the wall can affect the $f_{\mathrm{t}}$ of the masonry.

Since the tests at the bottom of the wall had a contribution of the interface grout/masonry much higher than the one of the masonry cone breakout, one used Equation (3) of Zamora et al. (2003) for uniform bond model and a value of $\tau_{0}$ equal to $0.9 \mathrm{MPa}$ to predict the pull-out capacity, resulting a value with an error of $13 \%$ relative to $N_{\text {exp }}^{B}$ (see Table 4). It is a good approximation that clearly evidences that bond failure at the grout/masonry interface played a primordial role on the failure of the tests at the bottom part of the wall. The two other values of $\tau_{0}$ proposed by Algeri et al. (2010), 0.53 
$\mathrm{MPa}$ and 1.64 MPa, underestimate and overestimate, respectively, the pull-out capacity associated with bond failure, as shown in Table 4 and Figure 5.

For the application of CCD related methods like the ones proposed by Zamora et al. (2003) and Allen et al. (2000), the values 14 and 24 were assumed for $k$ in Equation (7). They refer to cast-inplace headed bolts in concrete and clay masonry, respectively. The first provides the lowest value for the tensile capacity of all models, being very conservative, while the second provides a good approximation to $N_{\text {exp }}^{T}$, which had a higher contribution of the masonry cone breakout (see Table 4 and Figure 5). Since this type of model is considered the most appropriate approach for estimating the tensile capacity related to concrete or masonry breakout (CEB, 1994; Zamora et al., 2003), greater effort, experimental or numerical, needs to be done to correctly estimate the coefficient $k$.

The tensile capacity for cone failure calculated with the ACI 530 (2005) equation is overestimating $N_{\text {exp }}^{T}$ by a factor of 3.5 , which is considerably high and confirms the necessity to adequate the value of $k_{1}$ to the type of masonry. Arifovic \& Nielsen (2004) Equation (5) also predicts a high value for $N_{\text {exp }}^{T}$, close to the one of ACI 530 (2005), possibly because it was also calibrated for new clay brick masonry. On the other hand, the adapted Equation (2) predicts a pull-out force equal to $85 \mathrm{kN}$, which slightly overestimates $N_{\text {exp }}^{T}$ (error $=11 \%$ ), probably because is considering the entire embedment length as effective (see Table 4 and Figure 5).

The suitability of the models to the experimental results is very dependent on the typology of anchor and substrate the model was developed for and the calibration factors. In general, one can conclude that if the empirical coefficients $k, k_{1}$ and $k_{\mathrm{c}}$ affecting the pull-out capacities are not appropriate, the predictions will not express the experimental values. Studies have proven that significant amount of tests allow good calibrations of these coefficients (Farrow \& Klingner, 1995; Cook et al., 1998). Regarding strength reduction factors for design purposes, one must advise that due to the variability associated with the obtained results, these probably should be higher than the ones previously referred for each failure model. 


\section{IDEALIZED FORCE-DISPLACEMENT CURVES AND PERFORMANCE CRITERIA}

Since one is developing a seismic retrofit solution for existing structures, the research performed falls within the scope of the EC8-Part 3 (CEN/TC250, 2004) and the ASCE/SEI 41-13 (ASCE, 2014). Provisions of these standards are based on performance-based design methodology, specifically developed for existing buildings, to minimize or eliminate unnecessary seismic rehabilitation.

Performance-based design, as the name suggests, relies on the definition of performance levels to be achieved when designing the new structure or the rehabilitation measures. Prior to undertake the rehabilitation process, one needs to assess if the present condition of the structure is sufficient to achieve the desired performance level. If the building needs a seismic rehabilitation, the first step is to carry out an exhaustive survey of the structural characteristics, the site seismic hazards, the historic and social importance, among other considerations. Then the Rehabilitation Objectives should be established, defining suitable Target Building Performance Levels and Earthquake Hazard Levels combinations, for each goal, and the amount of goals to be accomplished. EC8 (CEN/TC250, 2004) addresses the rehabilitation goals as Limit States, and establishes three limits, each one corresponding to a certain return period, defined by each National Annex. The number of Limit States to be checked is defined in the same Annex. The performance levels/limit states besides reflecting the extent of damage that would be sustained by the building, also account for the safety level of its occupants during and after the event, the cost and time of repair, among others. EC8 (CEN/TC250, 2004) establishes three discrete levels, while ASCE/SEI 41-13 (ASCE, 2014) defines four. The additional level is the Operational $(\mathrm{O})$ performance level, which accounts for negligible damage on structural and nonstructural components, meaning extremely low risk to life safety, and ensures that all systems important for normal operation shall function. The costs associated with this performance level are very high, decreasing its feasibility. The three performance levels/limit states that have similar descriptions in ASCE/SEI 41-13 (ASCE, 2014) and EC8-Part 3 (CEN/TC250, 2004) are respectively: Immediate Occupancy (IO)-Damage Limitation (DL); Life Safety (LS)-Significant Damage (SD); and finally Collapse Prevention (CP)/Near Collapse (NC). 
For EC8-Part 3 (CEN/TC250, 2004), the limit states DL, SD, and NC correspond respectively to the following Earthquake Hazard Levels, defined by their return periods (respective probabilities of exceedance in 50 years, in parentheses): 225 years (20\%), 475 years (10\%), and 2475 years (2\%). Similar Earthquake Hazard Levels are established in ASCE/SEI 41-13 (ASCE, 2014), but they can be combined with all the performance levels, as already mentioned. The Basic Performance Objective for Existing Buildings (BPOE), considered to be a reasonable and commonly applied requirement for buildings retrofit, in the United States, consists of two goals: LS performance level for a probability of exceedance of $20 \%$ in 50 years, and CP for a probability of exceedance of $5 \%$ in 50 years. While the first goal can find a direct correspondence to the SD limit state in EC8-Part 3 (CEN/TC250, 2004), the second level is close to what is defined for the NC limit state. In particular, for heritage buildings and key facilities for society, there is an especial interest in limiting the damage caused by frequent seismic events.

The initial step towards idealized force-displacement curves is the definition of multi-linear envelopes based on the experimental curves - backbone curves. These were determined according to the methodology suggested by ASCE/SEI 41-13 (ASCE, 2014), which is directed towards the definition of analysis parameters and acceptance criteria for structural components without existing information. The backbone curve of each specimen was defined by connecting with linear segments the points corresponding to the peak displacement of the first cycle, of the different displacement levels.

Each backbone curve was then approximated to a multi-segmented curve, conforming to one of the types of curves provided by the standard for the definition of deformation or force-controlled actions (ASCE, 2014). The backbone curves of the specimens at the top of the wall, from herein addressed as WT.40.I.Top, were idealized into trilinear curves, while the ones of the specimens at the bottom of the wall, from herein addressed as WT.40.I.Bottom were approximated by quadrilinear curves, due to their clear residual force segment.

The final step was to average all the idealized curves of all specimens, into a single multi-linear equivalent idealization, per type of specimens (WT.40.I.Top and WT.40.I.Bottom), with distinct limits 
corresponding to different phases of the specimens' response, signaled with letters from A to E, as shown in Figure 6. The elastic phase goes from A to B, the strain hardening is comprehended between $\mathrm{B}$ and $\mathrm{C}$, and the strength degradation phase develops between $\mathrm{C}$ and $\mathrm{E}$. The latter phase can encompass the occurrence of non-negligible residual force between point $\mathrm{D}$ and $\mathrm{E}$. After point $\mathrm{E}$, there is a complete loss of load transmission capabilities. Curves fitting type 1 or 2 (ASCE, 2014), with the strain-hardening range characterized by the displacement at point $\mathrm{C}$ being two times higher or equal to the displacement at point $\mathrm{B}$, correspond to ductile behavior, and are classified as deformationcontrolled actions. Curves matching type 3 represent brittle or non-ductile behavior, therefore are always classified as force-controlled actions. While ASCE/SEI 41-13 (ASCE, 2014) states very clearly the difference between the two types of actions, EC8 (CEN/TC250, 2004) is not as clear.

To convert the backbone curves into trilinear and quadrilinear idealizations, one applied principles suggested by Tomaževič (1999) for bilinear and trilinear curves, with small alterations to better fit the present results, which are based on equalizing the total energy from the backbone curve and the one of the idealized curve (Moreira, 2015). The construction of the idealized curves relies on the definition of behavior limits on the experimental backbone curves - crack limit, maximum force, maximum displacement, and residual force - and the creation of idealized limits outside the curve - idealized elastic and ultimate limits. The following conditions were established to determine the curves: point B corresponds to the idealized elastic limit and it results from ensuring that the branch A-B passes through the crack limit established experimentally, by the displacement $d_{y}$; the curves can depict two pre-peak stiffnesses, thus the effective stiffness, $k_{\mathrm{e}}$, should take similar values to the ones of $k_{0}$; point $\mathrm{C}$ corresponds to $F_{\max } ; d_{\mathrm{u}}$ is calculated as already expressed in section 2.3 ; and the residual forces of WT.I.40.Bottom specimens were calculated by averaging the forces measured on the last two points of the backbone curves. The values of the parameters mentioned are presented in Table 1 .

For the WT.40.I.Top specimens' trilinear curves, points D and E were assumed to be coincident, since non-negligible residual force does not develop, and correspond to the ultimate state (see Figure 6a). For the WT.40.I.Bottom curve, the latter displacement takes the average value of $8.1 \mathrm{~mm}$ (values of $6.7 \mathrm{~mm}$ and $9.5 \mathrm{~mm}$, for WT.40.I.1A and WT.40.I.2B respectively) and was used to 
calculate $\mu$. The displacement of point $\mathrm{D}$ was determined through total energy balance between backbone and idealized curves, and displacement of point $\mathrm{E}$ corresponds to the maximum displacement (see Figure 6b).

The points referring to the different stages of the specimens' response, presented in Figure 6, have their coordinates defined in Table 5. The idealized curves developed are mostly within the envelope area of the backbone curves, confirming the good approximations (low $\mathrm{R}^{2}$ ) obtained between curves when the total energy is equalized. The coefficient $R^{2}$ was calculated as the sum of the squares of the vertical deviations between experimental and idealized curves, for each specimen. Specimen WT.40.I.1D presents the worse approximation due to its large post-peak displacements, as shown in Table 5. Stiffness $k_{\mathrm{e}}$ presented in Table 5 is slightly higher than the $k_{0}$ presented in Table 1 , because they were obtained through different methods. While the latter was determined through a linear least squares fitting to the linear portion of the experimental force-displacement curves, $k_{\mathrm{e}}$ results from the slope of the secant line between the origin and the crack limit (point B). As shown in Table 5, there is a higher variability associated with the WT.40.I.Top trilinear curve than with the WT.40.I.Bottom quadrilinear curve. The pre-cracking phase of the WT.40.I.Bottom specimens is very similar contributing greatly to the low CoVs.

The trilinear and quadrilinear curves obtained can be classified as ductile, since they respect the conditions already mentioned. Specimens WT.40.I.Bottom have idealized curves corresponding to type 1 curves, while WT.40.I.Top specimens' curves are closer to type 2 curves. Being the pullout response of these specimens a deformation-controlled action, performance criteria could be established in terms of displacement to be used in nonlinear procedures. Masonry-to-timber connections are primary components, which are needed to create effective load paths for the seismic demand. Thus, the acceptance criteria are established assuming this condition.

Acceptance criteria for displacement were determined according to ASCE/SEI 41-13 (ASCE, 2014) recommendations, which are similar to the suggestions of EC8-Part 3 (CEN/TC250, 2004) for the definition of global capacity models for assessment. Therefore, the IO/DL limit, $\Delta_{\mathrm{IO} / \mathrm{DL}}$, is defined by the deformation at which visible damage occurred but it cannot be greater than 0.67 the 
deformation limit for $\mathrm{LS} / \mathrm{SD}, \Delta_{\mathrm{LS} / \mathrm{SD}}$. The latter displacement is defined by 0.75 times the deformation at point $\mathrm{E}$ on the curves (see Figure 6), placing this limit after the peak load is achieved, for both WT.40.I.Top and WT.40.I.Bottom specimens. Finally, the CP/NC limit displacement, $\Delta_{\mathrm{CP} / \mathrm{NC}}$, corresponds to the displacement at point E, taking advantage of the capacity of the component to still carry seismic loads until complete fracture $\left(d_{\mathrm{u}}\right)$. For simplified linear procedures, based on the equal displacement rule (it considers a bilinear idealization of the backbone curve, where elastic and inelastic displacements are the same for structures beyond a given period range), and applied at component level, the resistant capacity of the connection should result from the product between the expected strength, $Q_{\mathrm{CE}}$, them-factor, and the appropriate knowledge factor (for existing elements). The first two are determined from the displacement for each performance level, while the second reflects the degree of information regarding the existing elements. For the present context, this value is taken equal to the unit and for new materials this factor is not applicable. $Q_{\mathrm{CE}}$ is the mean resistant capacity at the considered performance level and the $m$-factor is a modification factor that accounts for the expected ductility associated with the action at the deformation level under consideration. The latter is determined by the quotient of the intended displacement level for linear procedures by the yield displacement, multiplied by 0.75 . The $m$-factors for the IO/DL limit are very conservative, because of the low cracking limit. For the $\mathrm{CP} / \mathrm{NC}$ performance level the m-factors are higher than 1.5 and reflect the ductility observed experimentally. Deformations, $m$-factors, expected strengths $\left(Q_{\mathrm{CE}}\right)$ for each level — IO/DL, LS/SD, and CP/NC — are presented in Table 6.

EC8-Part 3 (CEN/TC250, 2004) recommends that for ductile elements, compliance with the requirements of each performance level should be made through verification of deformations, except when using the $q$-factor approach, which is done in terms of strength. The latter method is an elastic procedure that uses a design response spectrum reduced by factor $q$, which intends to account for the cyclic deformation and energy dissipation effects. Therefore, $q$-factors can be determined from experimental and numerical campaigns at the component level to be applied in verification and design of retrofit, as well as to assess the global behavior factor (Magenes et al., 2009), similarly to the $m$ factor introduced by ASCE/SEI 41-13 (ASCE, 2014). The $q^{0}$-factor (basic behavior factor) is defined 
as the ratio between the force the strengthening solution would experience if its response was completely elastic, $F_{\mathrm{el}, \max }$, and the yielding force $F_{\mathrm{y}}$ (Tomaževič, 1999; Frumento et al., 2009). Since the specimens behavior was not approximated by bilinear curves due to their shape, $k_{\mathrm{e}}$ of the trilinear curves was used to estimate $F_{\mathrm{el}, \max }$ at the displacement of $F_{\max }$ (point C). The values of $q^{0}$ proposed for the WT.I.Top and WT.I.Bottom specimens are within the interval commonly considered for the behavior factor of unreinforced masonry buildings, from 1.5 to 2.5 (CEN/TC250, 2004).

\section{DESIGN RECOMMENDATIONS}

As already mentioned, before engaging in any retrofit intervention, it is necessary to assess the present condition of the structure. If an intervention is required, one should then consider the technical criteria to take into account. Even if planning an intervention at component level, such as strengthening masonry-to-timber connections, the global perspective of the building always needs to be taken into consideration. This means that the intervention should not decrease the overall available ductility and if clear deficiencies are detected, they should be corrected or improved as much as possible.

Common retrofit design methodology encompasses the following stages: (1) conceptual design; (2) analysis; and (3) verifications (CEN/TC250, 2004). In the first step, there is the selection of the details of the intervention, the preliminary design of the strengthening solution, and a preliminary estimation of the modified stiffness of the retrofitted component. Particularly for historic constructions, the compatibility between existing and new materials, the reversibility of the intervention, or the limitations in terms of its execution demand a well-thought plan. The second step assesses the global response of the building, after the intervention, using linear or nonlinear analysis procedures. The final step consists of safety verifications. Retrofit design is then an iterative process conditioned by these three steps.

Considering all the information presented in the previous sections, and bearing in mind the three steps mentioned, a design procedure was proposed for retrofit with the studied strengthening solution. A basic retrofit goal is to design a connection for SD limit state, in order to maintain the primordial 
function of load transmission and still be able to explore some of its ductility. In addition, for historic structures it is important to keep damage under control, therefore the DL limit state should also be a retrofit goal. Procedures focus on these two steps, which occur at component level. After concluding the procedures, it is recommended to assess the response of the entire structure and verify if there is no decrease in global ductility.

Since the masonry-to-timber connections demonstrated a ductile behavior, the retrofit design should follow a displacement-based approach. Ideally, the seismic demand should be determined in terms of displacement, which would then be directly checked against the displacement limits corresponding to the performance levels (see Table 6), for nonlinear analysis. Since most procedures and codes are organized in terms of force-based design, is difficult to implement displacement checks for performance. Consequently, what is commonly done is, to carry out the design in terms of force and include towards the end of the process a displacement check (Priestley, 2000). In this case, the values determined for $Q_{\mathrm{CE}}$ and the behavior factors $\left(m\right.$ and $\left.q^{0}\right)$ can be applied as capacity limits.

The flowchart presented in Figure 7 proposed for retrofit design with injection anchors follows the common practice of force-based design, with displacement/ductility checks regarding the whole building. Therefore, design results from checking that the resisting force, $N_{\mathrm{R}}$, is higher than the design seismic demand per anchor, $N_{\mathrm{D}}$, calculated for the limit states established previously, SD and DL, according to EC8-Part 3 (CEN/TC250, 2004). Considering the failure modes and respective methods to calculate their strength capacity, described in section 3 , the design of the retrofitted connection must assure that the minimum of the capacities is higher than the seismic demand.

The quantification of the seismic demand is not part of the scope of this paper, but is recommended the use of dynamic methods and if possible nonlinear, as recommended by EC8 (CEN/TC250, 2004), ASCE/SEI 41-13 (ASCE, 2014), and several authors (Peralta et al., 2004; Costa et al. 2011; Theodossopoulos and Sinha 2013). The flowchart presented in Figure 7 considers the demand per anchor for design of the retrofit solution, therefore there is a need to establish a minimum number of anchors per storey (to anchor floors or walls). Tomaževič (1999) suggests that spacing 
between anchors should be around $1.5 \mathrm{~m}$ to $2.0 \mathrm{~m}$, which is close to the value suggested by ASCE/SEI 41-13 (ASCE, 2014) of approximately $2.4 \mathrm{~m}$.

For the injection anchors, one opted for the determination of the steel tie diameter, $d$, by ensuring that the steel tie capacity, $N_{s a}^{S D}$ is higher than the demand per anchor, $N_{\mathrm{D}, \mathrm{SD}}$. From this parameter, the diameter $d_{0}$ can be defined, considering that it should be between 1.5 and 3 times the diameter $d$. Together with material properties, $s$ (distance between anchors dependent on the thickness of the timber element and on the dimensions of the steel gussets), and $c$ (minimum wall coverage to the free end of the anchor), determine the value of $h_{\mathrm{c}}$, which is independent of the $h_{\text {ef }}$ to be chosen. One of the key steps of the procedure is the definition of $h_{\mathrm{ef}}$, which can control the expected failure mode of the connection and has to be equal to or lower than the thickness of the wall minus $c$. Existing recommendations for the installation of injection anchors in masonry suggest that $h_{\text {ef }}$ should be at most $2 / 3$ of the thickness of the wall or $c$ should be at least $50 \mathrm{~mm}$ (Algeri et al., 2010). Depending on the relationship between $h_{\mathrm{c}}$ and $h_{\mathrm{ef}}$, the verification is made for the failure mode that is most likely to occur - cone $\left(N_{c}^{S D}\right)$, bond $\left(N_{b}^{S D}\right)$, or combined cone-bond $\left(N_{c b}^{S D}\right)$ failures (see Figure 7). The capacity corresponding to the DL limit state, $N^{\mathrm{DL}}$, is difficult to quantify, since most formulae is developed for the ultimate state, unless experimental data is available.

Despite not being included in the procedure presented, improvement of the mechanical properties of masonry is an alternative or complementary option to changing the number of anchors or anchorage length. In fact, it can be even absolutely necessary, if the two connecting elements, the masonry wall and the timber element, are not in fair conditions to sustain static and dynamic actions. In historical constructions, is common to observe decay in timber elements embedded in the wall, caused by excessive humidity. As referred previously, the pullout tests carried out focused on the tensile behavior of the connection, but in reality the shear and flexure capacity of the connection are also engaged. Therefore, the assessment and the design retrofit of the connection should include the combined effect of these actions, especially shear and tensile stresses (Z. Lin et al., 2013). Another important aspect is to ensure that the bolted connection between the timber elements and the injection anchors enables effective load transmission and its capacity is superior to the seismic demand. This 
bolted connection can be designed to have a lower capacity than the one of the injections anchors and become the predominant failure mode, or to be higher and enable failure on the injection anchors' side. Design of the steel joints can be made according to EC3 - Part 1.8 (CEN/TC250, 2004b), while for the connection between the steel plate and the timber elements, the EC5 (CEN/TC 250/SC5, 2004) is suggested.

\section{CONCLUSIONS}

The analytical applications developed for the experimental results allowed a better understanding of the behavior observed experimentally, as well as, the analysis of strength prediction formulae and the definition of idealized force-displacement curves that can contribute for more practical uses of the data obtained. One intended at giving the first steps on force- and displacement-based design criteria for masonry-to-timber connections.

Based on theoretical failure modes and the ones observed experimentally, different strength prediction formulae can be applied to the injection anchors. Good estimations of the experimental values were obtained, if the existing formulae are adapted to the specificities of historical masonry. Especially the proposed combined cone-bond model seems capable of expressing the experimental phenomena, if a correct estimation of material properties is performed, such as the bond strength of the grout/masonry interface and the tensile strength of masonry. Further studies should be conducted to properly assess the influence of boundary conditions and compressive state of the wall on the pullout behavior, and how it could be incorporated in the existing formulae. Another important aspect to improve and validate the strength prediction formulae is the diversification of the input parameters by using data from other experimental campaigns or by developing numerical models of the existing tests and then carry out sensitivity analysis.

Based on their trilinear curves, the injection anchors' specimens were classified as ductile. Following a performance-based design approach, acceptance criteria based on displacement were proposed for each performance level (limit state), as suggested by ASCE/SEI 41-13 (ASCE, 2014) for ductile components. Considering that common practice is force-design oriented, force limits and 
$m$-factors were also proposed. The values obtained for the $q^{0}$ factors are within reasonable intervals suggested for masonry and close to the values obtained for the $m$-factors corresponding to performance level Collapse Prevention/Near Collapse. One must stress, that the performance criteria proposed are valid for the specimens tested and for the failure modes obtained, and they intend to be demonstrate how to transfer the experimental output into practical knowledge. Further experimental or numerical effort has to be done in order to study the influence of other failure modes, mechanical properties, and geometric characteristics.

The retrofit design approach recommended is oriented towards common practice, therefore is force-based designed. The procedure can be done with displacements instead of forces, if further effort is done on obtaining displacement-based formulae or by creating a database that can provide displacement acceptance criteria (as it was presented in this paper) for different situations.

Future works should focus as well on establishing the hysteretic rules, taking into consideration energy dissipation, strength and stiffness degradation, and pinching, and choose an appropriate hysteric model that can reproduce the experimental observations. Then, connections can be implemented as an element in numerical models of whole buildings and their contribution to the overall seismic response can be analyzed.

\section{ACKNOWLEDGEMENTS}

This work was partially funded by project FP7-ENV-2009-1-244123-NIKER of the $7^{\text {th }}$ Framework Program of the European Commission, which is gratefully acknowledged. Authors would like to thank the technical staff of the Structures Lab. of University of Minho for the assistance provided preparing and carrying out the tests and also, Monumenta, Ltd. for the construction of the specimens and Cintec ${ }^{\circledR}$ for the installation of the injection anchors. 
Design parameters for seismic retrofit with injection anchors

\section{REFERENCES}

ACI 318. 2005. Building Code Requirements for Structural Concrete ( ACI 318-05).

ACI 530. 2005. Building Code Requirements for Masonry Structures (ACI 530-05). Masonry Standars Joint Comittee.

ACI Commitee 349. 1990. Code Requirements for Nuclear Safety Related Concrete Structures (ACI 349-90).

Algeri, Cristiano, Elena Poverello, Giovanni Plizzari, and Ezio Giuriani. 2010. "Experimental Study on the Injected Anchors Behaviour on Historical Masonry." Advanced Materials Research 133134: 423-28. doi:10.4028/www.scientific.net/AMR.133-134.423.

Allen, Richard, J Gregg Borchelt, Richard E Klingner, and Rob Zobel. 2000. "Proposed Provisions for Design of Anchorage to Masonry." TMS Journal 18 (December): 35-60. http://www.masonrysociety.org/journalfiles/10012.pdf.

Appleton, João. 2005. Reabilitação de Edifícios “Gaioleiros.” 1st ed. Amadora: Edições Orion.

Arifovic, Fedja, and M. P. Nielsen. 2004. Strength of Anchors in Masonry.

ASCE. 2014. ASCE/SEI 41-13. Seismic Evaluation and Retrofit of Existing Buildings. USA.

Ballarini, R, S. P. Shah, and L. M. Keer. 1986. "Failure Characteristics of Short Anchor Bolts Embedded in a Brittle Material." In Royal Society of London, 35-54. London.

Bento, Rita, Mário Lopes, and Rafaela Cardoso. 2005. "Seismic Evaluation of Old Masonry Buildings. Part II: Analysis of Strengthening Solutions for a Case Study." Engineering Structures 27 (14): 2014-23. doi:10.1016/j.engstruct.2005.06.011.

Betti, Michele, Luciano Galano, and Andrea Vignoli. 2014. "Comparative Analysis on the Seismic Behaviour of Unreinforced Masonry Buildings with Flexible Diaphragms." Engineering Structures 61 (March). Elsevier Ltd: 195-208. doi:10.1016/j.engstruct.2013.12.038.

Bruneau, Michel. 1994. "State-of-the-Art Report on Seismic Performance of Unreinforced Masonry Buildings.” Journal of Structural Engineering 120 (1): 230 - . 
Design parameters for seismic retrofit with injection anchors

Cardoso, Rafaela, Mário Lopes, and Rita Bento. 2005. "Seismic Evaluation of Old Masonry Buildings. Part I: Method Description and Application to a Case-Study.” Engineering Structures 27: 2024-35. doi:10.1016/j.engstruct.2005.06.012.

CEB. 1994. Fastenings to Concrete and Masonry Structures. State-of-the-Art Report. London: Thomas Telford.

CEB. 2011. Design of Anchorages in Concrete. Fib Bulletin No. 58.

CEN/TC 250/SC5. 2004. EN 1995-1-1:2004. Eurocode 5 - Design of Timber Structures - Part 1-1: General - Common Rules and Rules for Buildings. Brussels, Belgium.

CEN/TC250. 2004a. EN 1998 - 3. Eurocode 8 - Design of Structures for Earthquake Resistance. Part 3 Assessment and Retrofitting of Buildings.

CEN/TC250. 2004b. EN 1993-1-8: 2004. Eurocode 3: Design of Steel Structures. Part 1.8: Design of Joints.

Cheok, G., and L. Phan. 1998. Post-Installed Anchors - A Literature Review. Maryland.

Cóias e Silva, V. 2007. Reabilitação Estrutural de Edifícios Antigos. Lisboa: Argumentum.

Cook, Ronald A, Jennifer L Burtz, and Marcus H Ansley. 2003. Design Guidelines and Specifications for Engineered Grouts. Gainsville, Florida.

Cook, Ronald A., and R C Konz. 2001. "Factors Influencing Bond Strength of Adhesive Anchors." ACI Structural Journal 98 (1): 76 - .

Cook, Ronald A., J Kunz, W Fuchs, and R C Konz. 1998. "Behavior and Design of Single Adhesive Anchors under Tensile Load in Uncracked Concrete.” ACI Structural Journal 95: 9-26.

Costa, Alexandre a., António Arêde, Aníbal Costa, and Carlos Sousa Oliveira. 2011. "Out-of-Plane Behaviour of Existing Stone Masonry Buildings: Experimental Evaluation." Bulletin of Earthquake Engineering 10 (1): 93-111. doi:10.1007/s10518-011-9332-9.

Eligehausen, R., and T. Balogh. 1995. "Behavior of Fasteners Loaded in Tension in Cracked Reinforced Concrete.” ACI Structural Journal 92 (3): 365-78.

Eligehausen, R., and G. Sawade. 1989. "Fracture Mechanics Based Description of the Pull-out Behavior of Headed Studs Embedded in Concrete." In Fracture Mechanics of Concrete 
Design parameters for seismic retrofit with injection anchors

Structures. From Theory to Application, edited by L. Elfgren Ed., 263-81. London: Chapman \& Hall.

EOTA. 2010. ETAG 029. Guideline for European Technical Approval of Metal Injection Anchors for Use in Masonry.

EOTA-TR 029. 2007. Design of Bonded Anchors - TR 029.

Farrow, C. B., and R E Klingner. 1995. "Tensile Capacity of Anchors with Partial or Overlapping Failure Surfaces: Evaluation of Existing Formulas on an LRFD Basis." ACI Structural Journal 92 (6): 698-709.

Frocht, MM. 1931. "Recent Advances in Photoelasticity." ASME Trans. 55 (September-December): $135-53$.

Frumento, Sara, Guido Magenes, Paolo Morandi, and Gian Michele Calvi. 2009. Interpretation of Experimental Shear Tests on Clay Brick Masonry Walls and Evaluation of Q-Factors for Seismic Design. Pavia: IUSS Press.

Fuchs, Werner, R Eligehausen, and John E Breen. 1995. "Concrete Capacity Design (CCD) Approach for Fastening to Concrete.” Aci Structural Journal 92 (1): 73-94.

Kim, Sang-Cheol, and Donald W. White. 2004. "Nonlinear Analysis of a One-Story Low-Rise Masonry Building with a Flexible Diaphragm Subjected to Seismic Excitation.” Engineering Structures 26 (14): 2053-67. doi:10.1016/j.engstruct.2004.06.008.

Lin, Tsu Jung, and James M. LaFave. 2012. "Experimental Structural Behavior of Wall-Diaphragm Connections for Older Masonry Buildings.” Construction and Building Materials 26: 180-89. doi:10.1016/j.conbuildmat.2011.06.008.

Lin, Zhibin, Jian Zhao, and Derek Petersen. 2013. "Failure Analysis of Anchors in Shear under Simulated Seismic Loads." Engineering Failure Analysis 31. Elsevier Ltd: 59-67. doi:10.1016/j.engfailanal.2013.01.017.

Lourenço, Paulo B., Nuno Mendes, Luís F. Ramos, and Daniel V. Oliveira. 2011. "Analysis of Masonry Structures Without Box Behavior.” International Journal of Architectural Heritage 5 (4-5): 369-82. doi:10.1080/15583058.2010.528824. 
Magenes, Guido, Claudio Modena, F. da Porto, and Paolo Morandi. 2009. "Seismic Behavior and Design of New Masonry Buildings: Recent Developments and Consequent Effects on Design Codes." In Eurocode 8 Perspectives from the Italian Standpoint Workshop, edited by E. Cosenza, 199-212. Napoly, Italy.

Mascarenhas, Jorge. 2004. Sistemas de Construção - V, O Edifício de Rendimento Da Baixa Pombalina de Lisboa. 2nd ed. Lisboa: Livros Horizonte.

Moreira, S. 2015. "Seismic Retrofit of Masonry-to-Timber Connections in Historical Constructions." University of Minho.

Moreira, Susana, Luís F. Ramos, Daniel V. Oliveira, and Paulo B. Lourenço. 2014. "Experimental Behavior of Masonry Wall-to-Timber Elements Connections Strengthened with Injection Anchors." Engineering Structures 81 (December). Elsevier Ltd: 98-109. doi:10.1016/j.engstruct.2014.09.034.

Obata, Makoto, Michio Inoue, and Yoshiaki Goto. 1998. "The Failure Mechanism and the Pull-out Strength of a Bond-Type Anchor near a Free Edge." Mechanics of Materials 28 (1-4): 113-22. doi:10.1016/S0167-6636(97)00052-5.

Paganoni, Sara, and Dina D’Ayala. 2014. “Testing and Design Procedure for Corner Connections of Masonry Heritage Buildings Strengthened by Metallic Grouted Anchors." Engineering Structures 70: 278-93. doi:10.1016/j.engstruct.2014.03.014.

Park, R. 1989. "Evaluation of Ductility of Structures and Structural Assemblages from Laboratory Testing.” Bulletin of the New Zealand Society For Earthquake Engineering 22 (2): 155-66.

Peralta, David F, Joseph M Bracci, and Mary Beth D Hueste. 2004. "Seismic Behavior of Wood Diaphragms in Pre-1950s Unreinforced Masonry Buildings." Journal of Structural Engineering 130 (12): 2040-51. doi:10.1061/(ASCE)0733-9445(2004)130:12(2040)).

Piccinin, R, R Ballarini, F Asce, and S Cattaneo. 2010. "Linear Elastic Fracture Mechanics Pullout Analyses of Headed Anchors in Stressed Concrete," no. June: 761-68.

Priestley, M J N. 2000. "Performance Based Seismic Design.” In 12th World Conference on Earthquake Engineering, 1:1-22. 
Senaldi, Ilaria, Guido Magenes, Andrea Penna, Alessandro Galasco, and Maria Rota. 2014. "The Effect of Stiffened Floor and Roof Diaphragms on the Experimental Seismic Response of a FullScale Unreinforced Stone Masonry Building.” Journal of Earthquake Engineering 18 (3): 40743. doi:10.1080/13632469.2013.876946.

Theodossopoulos, Dimitris, and Braj Sinha. 2013. "A Review of Analytical Methods in the Current Design Processes and Assessment of Performance of Masonry Structures." Construction and Building Materials 41: 990-1001. doi:10.1016/j.conbuildmat.2012.07.095.

Tomaževič, Miha. 1999. Earthquake-Resistant Design of Masonry Buildings. Edited by A. S. Elnashai and P. J. Dowling. Imperial College Press.

Zamora, N. A., Ronald A Cook, R C Konz, and G. R. Consolazio. 2003. "Behavior and Design of Single, Headed and Unheaded, Grouted Anchors under Tensile Load.” ACI Structural Journal 100 (2): 222-30. doi:10.14359/12486. 


\section{List of Figures}

Figure 1 Injection anchors for connections: (a) sketch of application (Cóias e Silva, 2007); (b) possible failure modes (top view)

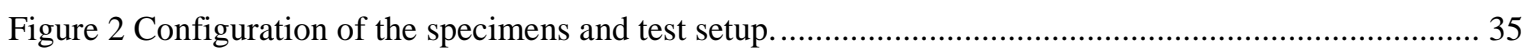

Figure 3 Force-displacement based on $s_{\mathrm{T}}$ : (a) specimens at the top; (b) specimens at the top................... 36

Figure 4 Failure modes: (a) substrate cone failure; and (b) combined cone-bond failure (adapted from Zamora et al., 2003) 37

Figure 5 Comparison between experimental results and behavioral models......................................... 38

Figure 6 Idealized trilinear/quadrilinear curves of the specimens: (a) WT.I. Top; (b) WT.I.Bottom. ........... 39

Figure 7 Flowchart for the design of injection anchors.

\section{List of Tables}

Table 1 Main experimental parameters determined from the pullout tests on injection anchors.

Table 2 Summary of methods to determine the nominal tensile load conical concrete/masonry breakout, $N_{\mathrm{c}}$.

Table 3 Summary of methods to determine the nominal tensile load for combined cone-bond failure, $N_{\mathrm{cb} . .} 43$

Table 4 Comparison between predicted tensile capacities and experimental values.

Table 5 Parameters relative to the idealized curves.

Table 6 Proposed acceptance criteria for connections subjected to pullout. 46 


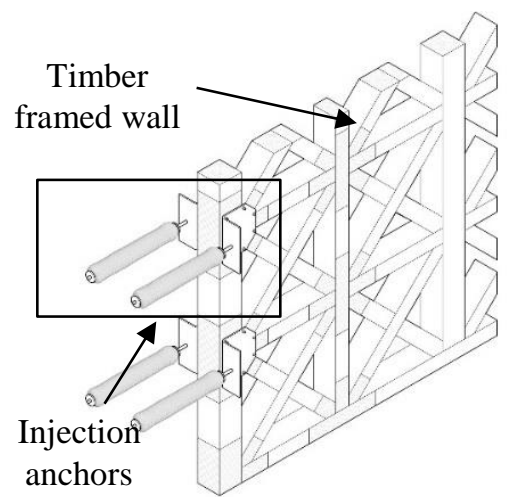

(a)

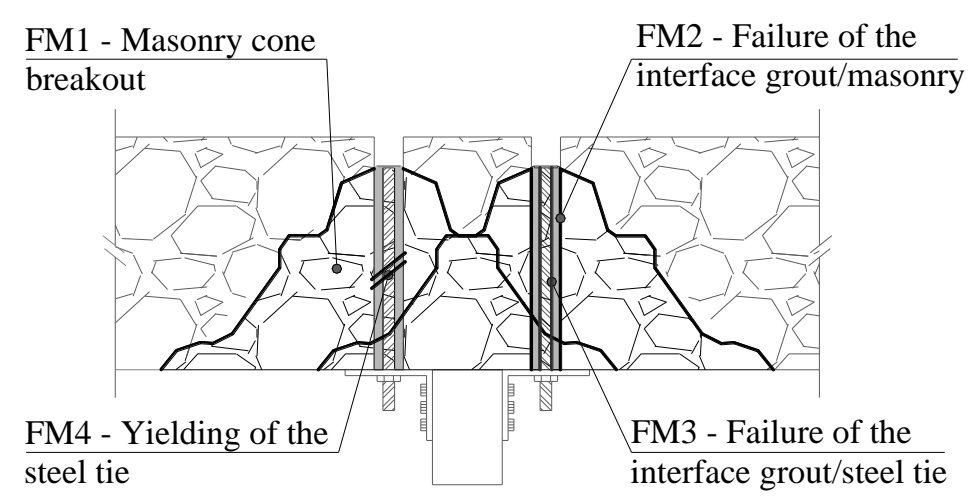

(b)

Figure 1 Injection anchors for connections: (a) sketch of application (Cóias e Silva, 2007); (b) possible failure modes (top view). 
Design parameters for seismic retrofit with injection anchors

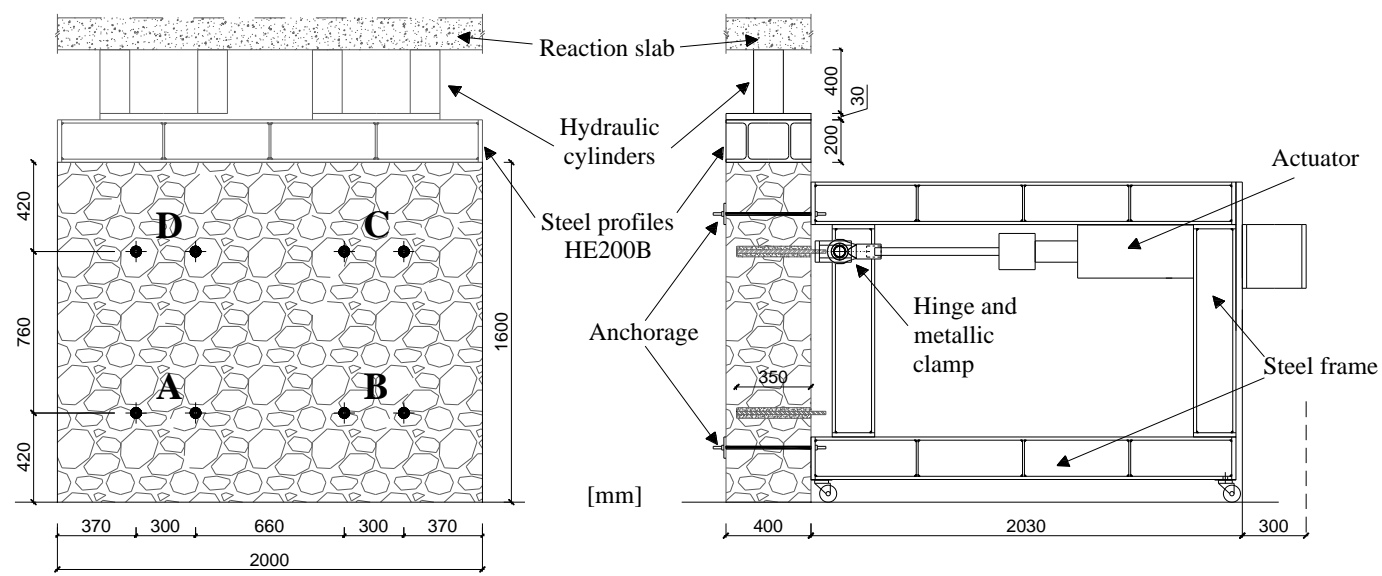

Figure 2 Configuration of the specimens and test setup. 
Design parameters for seismic retrofit with injection anchors

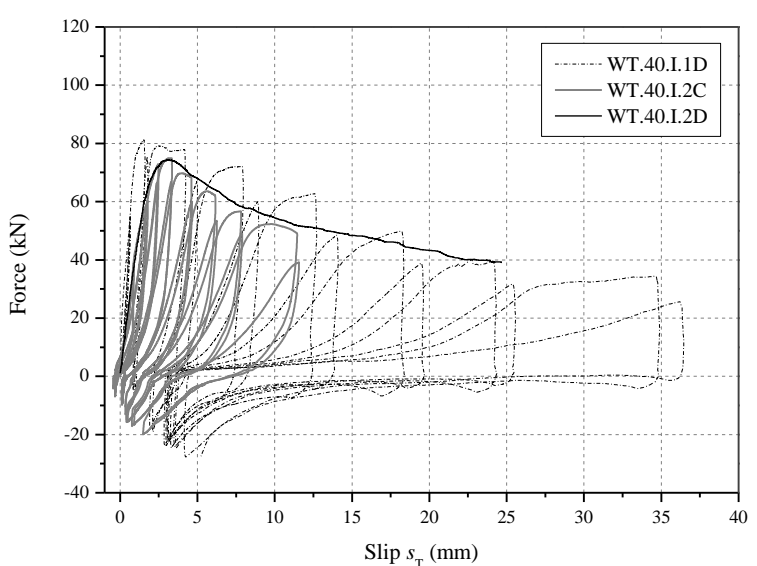

(a)

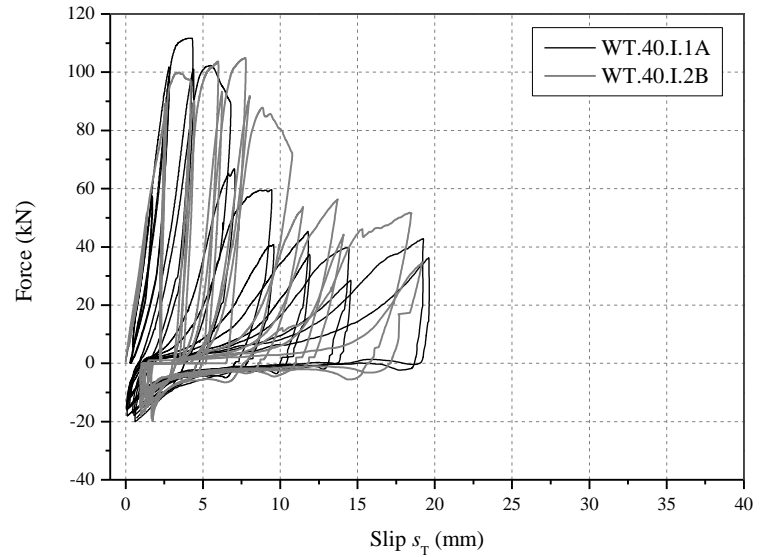

(b)

Figure 3 Force-displacement based on $s_{\mathrm{T}}$ : (a) specimens at the top; (b) specimens at the top. 


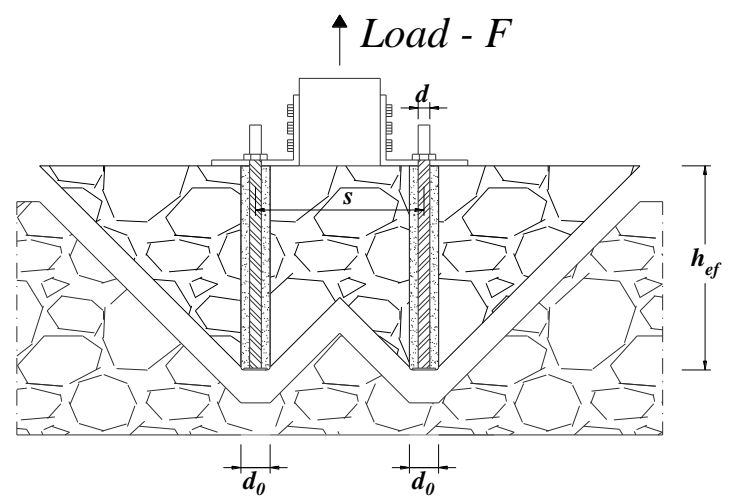

(a)

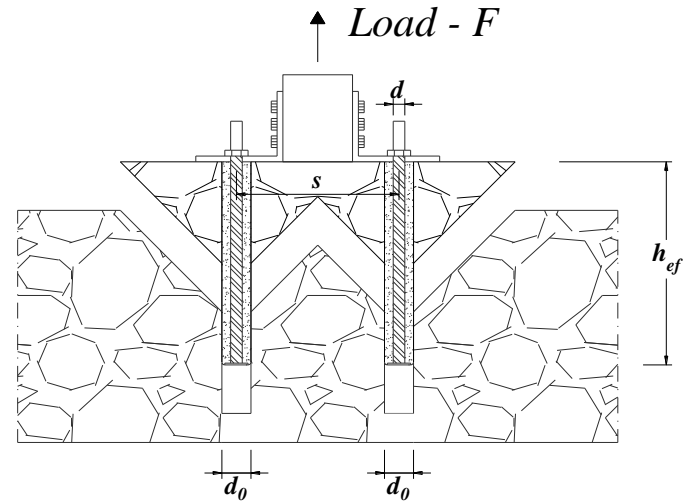

(b)

Figure 4 Failure modes: (a) substrate cone failure; and (b) combined cone-bond failure (adapted from Zamora et al., 2003) 
Design parameters for seismic retrofit with injection anchors

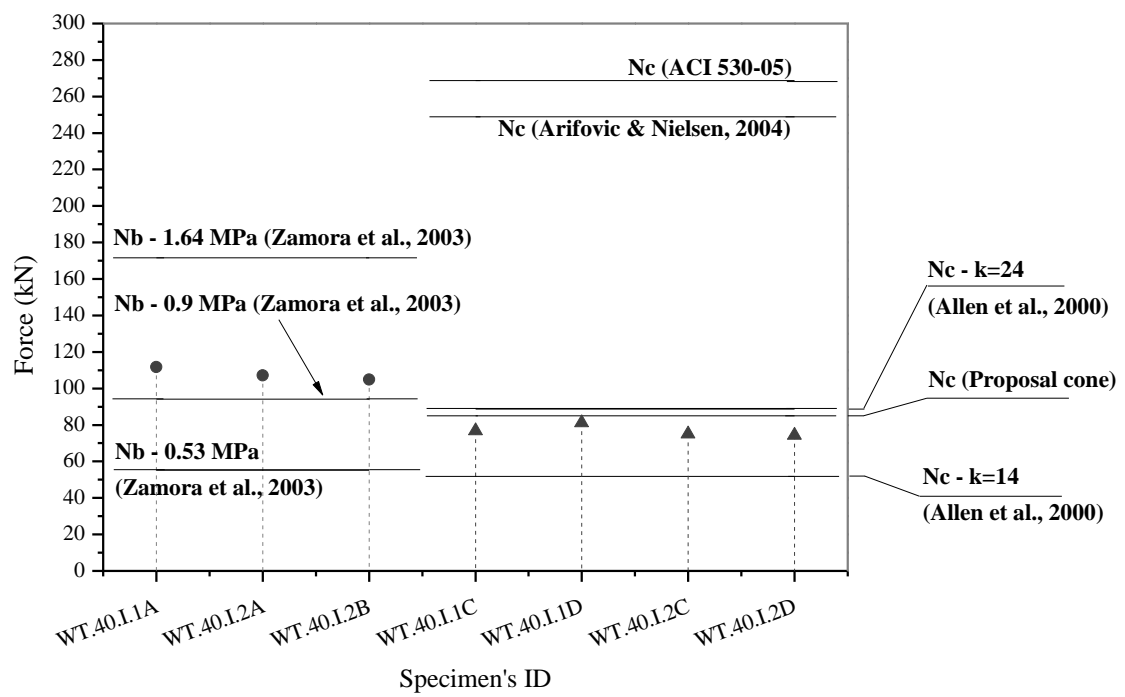

Figure 5 Comparison between experimental results and behavioral models. 
Design parameters for seismic retrofit with injection anchors

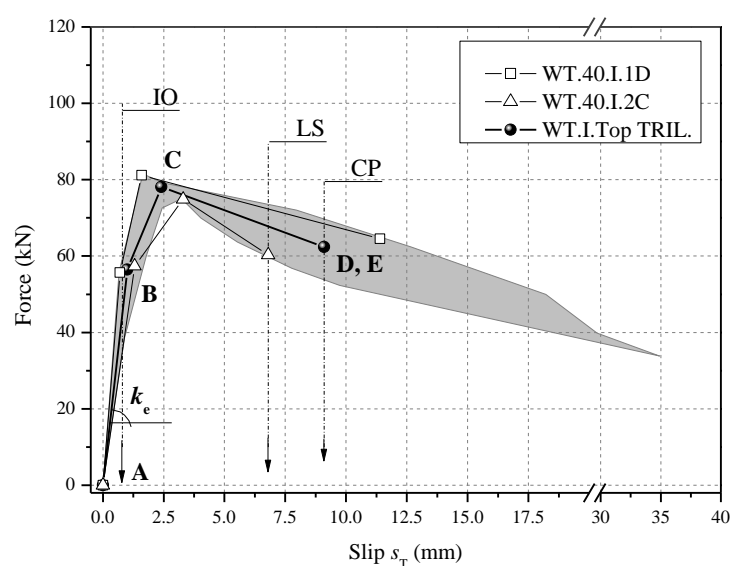

(a)

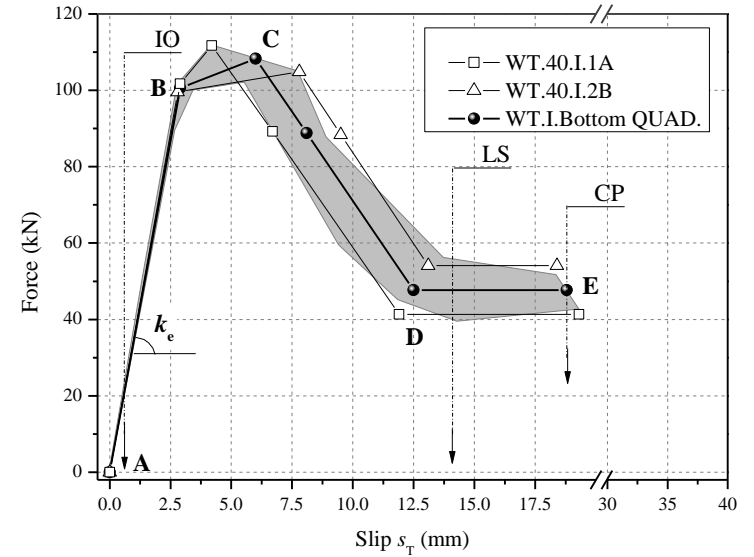

(b)

Figure 6 Idealized trilinear/quadrilinear curves of the specimens: (a) WT.I. Top; (b) WT.I.Bottom. 


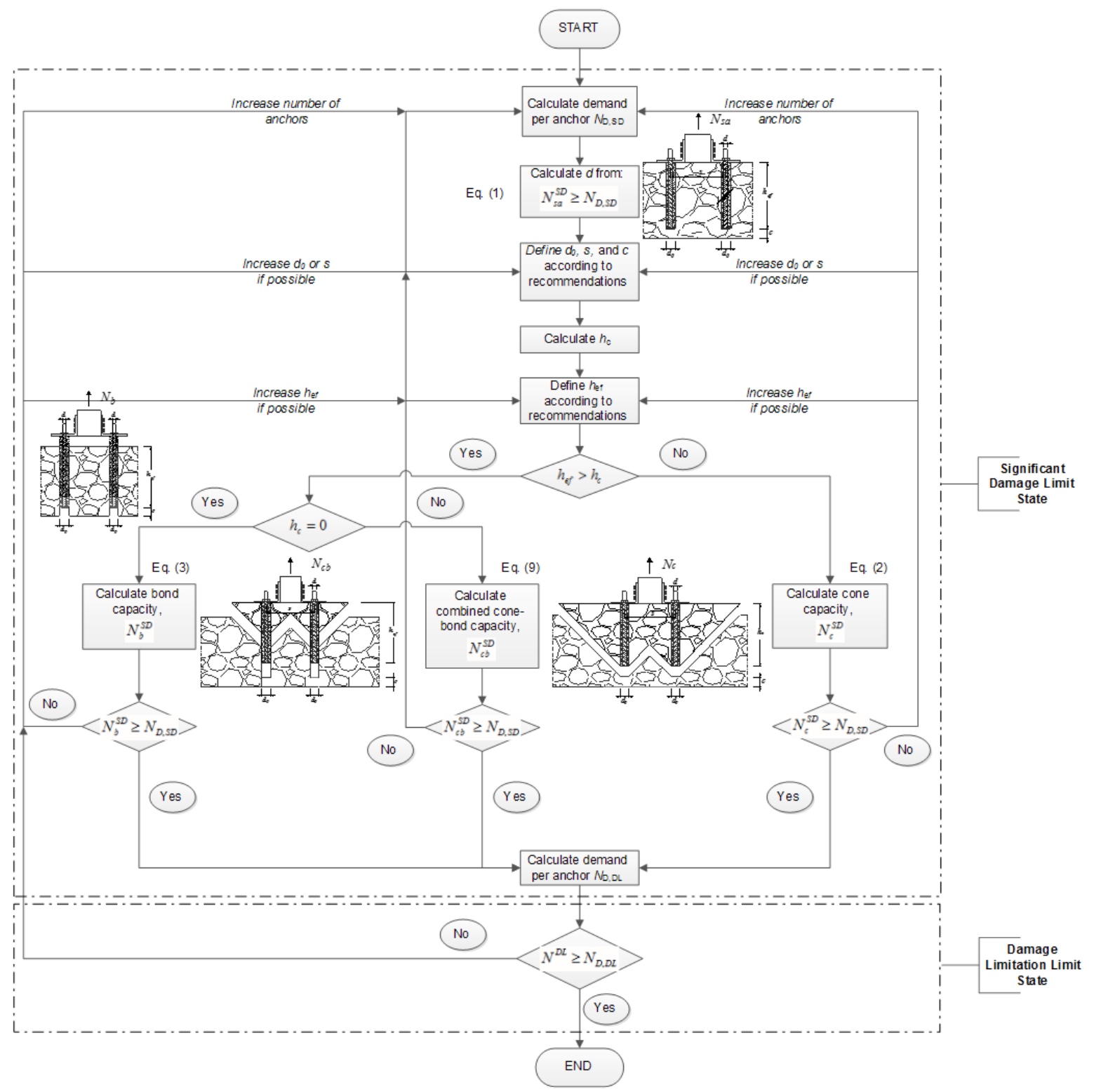

Figure 7 Flowchart for the design of injection anchors. 
Design parameters for seismic retrofit with injection anchors

Table 1 Main experimental parameters determined from the pullout tests on injection anchors.

\begin{tabular}{|c|c|c|c|c|c|c|}
\hline Specimen & Type of pullout & $\begin{array}{l}F_{\max } \\
(\mathbf{k N})\end{array}$ & $\begin{array}{c}k_{0} \\
(\mathbf{k N} / \mathbf{m m})\end{array}$ & $d_{\mathbf{y}}(\mathrm{mm})$ & $d_{\mathbf{u}}(\mathbf{m m})$ & $\boldsymbol{\mu}$ \\
\hline WT.40.I.1A & Cyclic & 111.7 & 33.3 & 2.0 & 6.30 & 3.2 \\
\hline WT.40.I.2A & Cyclic & 107.2 & - & - & - & - \\
\hline WT.40.I.2B & Cyclic & 104.9 & 35.1 & 2.7 & 9.53 & 3.5 \\
\hline \multicolumn{2}{|c|}{ Bottom average } & 107.9 & 34.2 & 2.6 & 8.2 & 3.4 \\
\hline \multicolumn{2}{|c|}{$\operatorname{CoV}(\%)$} & 3.2 & 3.7 & 5.4 & 23.6 & 18.3 \\
\hline WT.40.I.1C & Monotonic & 76.8 & 18.2 & 3.1 & 16.8 & 5.4 \\
\hline WT.40.I.1D & Cyclic & 81.2 & 62.0 & 0.7 & 12.1 & 18.6 \\
\hline WT.40.I.2C & Cyclic & 75.0 & 40.9 & 0.9 & 6.7 & 7.4 \\
\hline WT.40.I.2D & Monotonic & 74.3 & 40.2 & 1.3 & 7.7 & 5.9 \\
\hline \multicolumn{2}{|c|}{ Top average } & 76.8 & 40.3 & 1.5 & 10.8 & 9.4 \\
\hline \multicolumn{2}{|c|}{$\mathrm{CoV}(\%)$} & 4.0 & 44.4 & 74.5 & 42.7 & 66.7 \\
\hline
\end{tabular}


Design parameters for seismic retrofit with injection anchors

Table 2 Summary of methods to determine the nominal tensile load conical concrete/masonry breakout, $N_{\mathrm{c}}$.

\begin{tabular}{ccc}
\hline Method & Type of anchor & Conical failure $-\mathbf{N}_{\mathbf{c}}(\mathbf{N})$ \\
\hline ACI 530 (2005) & $\begin{array}{c}\text { Headed anchors in regular } \\
\text { masonry }\end{array}$ & $0.33 A_{N c} \sqrt{f_{m}^{\prime}}$ \\
$\begin{array}{c}\text { Arifovic \& Nielsen } \\
(2004)\end{array}$ & $\begin{array}{c}\text { Bonded anchors in brick } \\
\text { masonry }\end{array}$ & $\frac{\mathrm{A}_{N c}}{A_{N c o}} 0.96 \sqrt{f_{m}^{\prime}} h_{e f}\left[h_{e f}+\mathrm{d}\right]$ \\
$\begin{array}{c}\text { Zamora et al. (2003) } \\
\text { Allen et al. (2000) } \\
\text { "5-X" framework }\end{array}$ & Headed anchors in masonry & $\frac{\mathrm{A}_{N c}}{A_{N c o}} \psi_{s, N} \psi_{e c, N} 12.6 \sqrt{f_{c}^{\prime}} h_{e f}^{1.5}$ \\
\hline
\end{tabular}


Design parameters for seismic retrofit with injection anchors

Table 3 Summary of methods to determine the nominal tensile load for combined cone-bond failure, $N_{\mathrm{cb}}$

\begin{tabular}{|c|c|c|c|}
\hline Method & Type of anchor & Combined cone-bond failure $-N_{c b}(\mathrm{~N})$ & \\
\hline $\begin{array}{l}\text { Cook et al. } \\
\text { (1998) }\end{array}$ & $\begin{array}{l}\text { Adhesive anchors for } \\
\text { concrete - Single anchor }\end{array}$ & $\begin{array}{l}0.92 h_{c}^{2} \sqrt{f_{c}^{\prime}}+\pi \tau d\left(h_{e f}-h_{c}\right) \\
, \text { if } h_{e f}>h_{c} \text { and } h_{c}=\frac{\tau \pi d}{1.8 \sqrt{f_{c}^{\prime}}}\end{array}$ & (8) \\
\hline Proposal & $\begin{array}{l}\text { Grouted anchors for } \\
\text { historic masonry - Two } \\
\text { parallel anchors }\end{array}$ & $\begin{array}{c}A_{N c}\left(h_{c}\right) \cdot k \sqrt{f_{m}^{\prime}}+2 \pi \cdot d_{0} \cdot \tau_{0} \cdot\left(h_{e f}-h_{c}\right) \\
\text { if } 0 \leq h_{c} \leq h_{e f}, s \leq 2 h_{c} \text { and with } \\
h_{c}=\frac{\pi \cdot d_{0} \cdot \tau_{0}-s \cdot k \sqrt{f_{m}^{\prime}}}{4 \cdot k \sqrt{f_{m}^{\prime}}}\end{array}$ & (9) \\
\hline
\end{tabular}


Table 4 Comparison between predicted tensile capacities and experimental values.

\begin{tabular}{|c|c|c|c|c|c|c|}
\hline \multirow{2}{*}{$\begin{array}{l}\text { Prediction } \\
\text { Equation }\end{array}$} & \multicolumn{2}{|c|}{ Masonry cone breakout } & \multicolumn{2}{|c|}{ Bond failure } & \multicolumn{2}{|c|}{ Combined cone-bond failure } \\
\hline & $N_{c}$ & $N_{c} / N_{e x p}^{T}$ & $N_{b}$ & $N_{b} / N_{e x p}^{B}$ & $N_{\text {cb }}$ & $N_{c b} / N_{e x p}$ \\
\hline $\begin{array}{c}\text { ACI 530 } \\
(2005)\end{array}$ & 268.8 & 3.5 & - & - & - & - \\
\hline Allen et al. & $51.8(\mathrm{k}=14)$ & 0.7 & $55.4(\tau=0.53)$ & 0.5 & - & - \\
\hline$(2000) /$ & $88.9(\mathrm{k}=24)$ & 1.2 & $94.2(\tau=0.90)$ & 0.9 & - & - \\
\hline $\begin{array}{c}\text { Zamora et al. } \\
\text { (2003) }\end{array}$ & 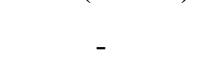 & - & $171.6(\tau=1.64)$ & 1.6 & - & - \\
\hline $\begin{array}{c}\text { Arifovic \& } \\
\text { Nielsen (2004) }\end{array}$ & 248.9 & 3.2 & - & - & - & - \\
\hline Proposal & 85.0 & 1.1 & - & - & $\begin{array}{l}91.1 \text { (Bot.) } \\
76.7 \text { (Top) }\end{array}$ & $\begin{array}{l}0.8 \\
1.0\end{array}$ \\
\hline
\end{tabular}


Table 5 Parameters relative to the idealized curves.

\begin{tabular}{|c|c|c|c|c|c|c|c|c|c|c|c|}
\hline \multirow[b]{2}{*}{ Specimens } & \multicolumn{2}{|c|}{ B } & \multicolumn{2}{|c|}{$\mathbf{C}$} & \multicolumn{2}{|c|}{ D } & \multicolumn{2}{|c|}{$\mathbf{E}$} & \multirow{2}{*}{$\begin{array}{c}k_{\mathrm{e}} \\
(\mathbf{k N} / \\
\mathbf{m m})\end{array}$} & \multirow[b]{2}{*}{$\boldsymbol{\mu}$} & \multirow[b]{2}{*}{$R^{2}$} \\
\hline & $\begin{array}{c}\mathrm{d} \\
(\mathrm{mm})\end{array}$ & $\begin{array}{c}\mathbf{F} \\
(\mathbf{k N})\end{array}$ & $\begin{array}{c}\mathbf{d} \\
(\mathrm{mm})\end{array}$ & $\begin{array}{c}\mathbf{F} \\
(\mathbf{k N})\end{array}$ & $\begin{array}{c}\mathbf{d} \\
(\mathrm{mm})\end{array}$ & $\begin{array}{c}\mathbf{F} \\
(\mathbf{k N})\end{array}$ & $\begin{array}{c}\mathrm{d} \\
(\mathrm{mm})\end{array}$ & $\begin{array}{c}\mathbf{F} \\
(\mathbf{k N})\end{array}$ & & & \\
\hline WT.40.I.1D & 0.7 & 55.7 & 1.6 & 81.2 & - & - & 11.4 & 64.5 & 75.8 & 15.5 & 168 \\
\hline WT.40.I.2C & 1.3 & 57.4 & 3.3 & 74.9 & - & - & 6.8 & 60.3 & 43.5 & 5.1 & 55 \\
\hline $\begin{array}{l}\text { WT.40.I. } \\
\text { Top }\end{array}$ & 1.0 & 56.5 & 2.4 & 78.1 & - & - & 9.1 & 62.4 & 55.1 & 8.9 & - \\
\hline $\mathrm{CoV}(\%)$ & 40 & 2 & 50 & 6 & - & - & 36 & 5 & 38 & 71 & - \\
\hline WT.40.I.1A & 2.9 & 101.7 & 4.2 & 111.7 & 11.9 & 41.3 & 19.3 & 41.3 & 34.8 & 2.3 & 61 \\
\hline WT.40.I.2B & 2.8 & 99.6 & 7.8 & 104.9 & 13.1 & 54.1 & 18.4 & 54.1 & 35.1 & 3.3 & 82 \\
\hline $\begin{array}{l}\text { WT.40.I. } \\
\text { Bottom }\end{array}$ & 2.9 & 100.6 & 6.0 & 108.3 & 12.5 & 47.7 & 18.8 & 47.7 & 35.0 & 2.8 & - \\
\hline $\mathrm{CoV}(\%)$ & 2 & 1 & 42 & 4 & 7 & 19 & 3 & 19 & 1 & 27 & - \\
\hline
\end{tabular}


Design parameters for seismic retrofit with injection anchors

Table 6 Proposed acceptance criteria for connections subjected to pullout.

\begin{tabular}{cccccccccccc}
\hline \multirow{3}{*}{ Set of tests } & \multicolumn{3}{c}{$\mathbf{I O / D L}$} & \multicolumn{3}{c}{$\mathbf{L S / S D}$} & \multicolumn{3}{c}{$\mathbf{C P / N C}$} \\
& $\begin{array}{c}\boldsymbol{\Delta}_{\mathbf{I O} / \mathbf{D L}} \\
(\mathbf{m m})\end{array}$ & $\begin{array}{c}\boldsymbol{Q}_{\mathbf{C E}} \\
(\mathbf{k N})\end{array}$ & $\boldsymbol{m}$ & $\begin{array}{c}\boldsymbol{\Delta}_{\mathbf{L S} / \mathbf{S D}} \\
(\mathbf{m m})\end{array}$ & $\begin{array}{c}\mathbf{Q}_{\mathbf{C E}} \\
(\mathbf{k N})\end{array}$ & $\boldsymbol{m}$ & $\begin{array}{c}\boldsymbol{\Delta}_{\mathbf{C P} / \mathbf{N C}} \\
(\mathbf{m m})\end{array}$ & $\begin{array}{c}\boldsymbol{Q}_{\mathbf{C E}} \\
(\mathbf{k N})\end{array}$ & $\boldsymbol{m}$ & $\boldsymbol{q}^{\mathbf{0}}$ \\
\hline WT.I.Top & 0.8 & 44.1 & 0.6 & 6.8 & 67.8 & 1.3 & 9.1 & 62.4 & 1.8 & 1.7 \\
WT.I.Bottom & 2.4 & 83.9 & 0.6 & 14.1 & 47.7 & 1.2 & 18.8 & 47.7 & 1.6 & 1.9 \\
\hline
\end{tabular}

